\title{
Natural Oligopoly Responses, Repeated Games, and Coordinated Effects in Merger Analysis: A Perspective and Research Agenda
}

\author{
Joseph Farrell ${ }^{1}$ D . Jonathan B. Baker ${ }^{2}$
}

Accepted: 22 December 2020 / Published online: 9 February 2021

(c) The Author(s), under exclusive licence to Springer Science+Business Media, LLC part of Springer Nature 2021

\begin{abstract}
When the 1968 Merger Guidelines were drafted, both the economics and antitrust literatures addressed how competition could be softened when oligopolists anticipated the natural and predictable responses of their rivals to their competitive moves, such as price cuts or output expansion. But when economists developed new models of oligopoly behavior, and of coordinated effects in particular, the older ideas were dropped - until the 2010 Guidelines, when the older ideas were reincorporated along with the newer ones. Our article points out limitations of the workhorse repeated game model of oligopoly conduct for analyzing coordinated effects of mergers, and suggests ways to make that model more realistic. We also identify important research questions that are raised when attempting to account for oligopolists' natural and predictable responses in evaluating the consequences of mergers, and suggest studying Stackelberg reactions as a way to make progress in doing so.
\end{abstract}

Keywords Coordinated effects $\cdot$ Merger guidelines $\cdot$ Oligopoly $\cdot$ Conjectural variations

\section{Introduction}

The first merger guidelines — which were issued by the U.S. Department of Justice in 1968 - did not mention collusion or coordinated effects. They simply observed that "a concentrated market structure, where a few firms account for a large share of the sales, tends to discourage vigorous price competition by the firms in the market."

Joseph Farrell

joseph.farrell@berkeley.edu

Jonathan B. Baker

jbaker@wcl.american.edu

1 Department of Economics, University of California, Berkeley, CA, USA

2 American University Washington College of Law, Washington, DC, USA 
That understanding was consistent with the industrial organization economics learning of the day (e.g., Chamberlin 1962).

The economic model that underlay the literature and the Guidelines viewed supracompetitive prices as the likely outcome of oligopoly interactions with nonzero conjectural variations ${ }^{1}$ : Competition would typically be softened when oligopolists recognize their interdependence and anticipate the natural and predictable reactions of their rivals to their price changes. That view was endorsed in prior academic writing by Donald Turner, the then-head of the Antitrust Division (Turner 1962). Turner explained that a rational oligopolist understands that its rivals will "inevitably react" when it cuts price "because otherwise the price cut will make a substantial inroad on their sales." As such "inevitable" responses undermine the price-cutter's reward of a gain in market share, each seller will rationally refrain from price competition. ${ }^{2}$ Some economic models incorporated conjectural variations to capture natural and predictable reactions, and empirical economists sought to estimate conjectural variations. ${ }^{3}$

The next Merger Guidelines-which were issued in 1982 and were modified slightly in 1984 - brought a different economic model to understanding the competitive effects of mergers in oligopoly markets. Outside of markets with dominant firms, those Guidelines were concerned about the threat of collusion (in the sense of consciously coordinated behavior). The Guidelines discussed concentration measures and the significance of various aspects of market structure, conduct, and performance in terms of their ability to facilitate "cartels," "collusion," and "collusive agreements." That meant evaluating the effect of those factors on whether firms could reach consensus and deter cheating-consistent with the economic approach that was suggested by Stigler (1964). ${ }^{4}$ That framework drew attention away from the softening of competition and the coordinated outcomes that Turner saw as arising simply from natural and predictable reactions of rivals. As we have discussed elsewhere (Baker and Farrell 2020), this collusion-centered perspective characterized antitrust commentators of that era associated with the Chicago school.

By 1992, with the game theory revolution in microeconomics well underway, the new Horizontal Merger Guidelines famously introduced a distinction between coordinated and unilateral conduct, and linked each to a branch of economic theory:

\footnotetext{
1 The familiar static Bertrand and Cournot models assume zero conjectural variations in price and quantity, respectively. The pre-game theory generation of Industrial Organization economists were not as focused on static models with zero conjectural variations as Industrial Organization economists are today (e.g., Bain 1968). Schmalensee (2012, p. 172) criticizes this nearly exclusive focus.

2 To anticipate a distinction we make later, Turner was clearly not talking about firms that pick out a coordinated price and use price cuts to force rivals back to it.

${ }^{3}$ For a discussion and citations to early literature, see Martin (1993, pp. 24-27; a more recent policyoriented survey is UK Office of Fair Trading (2011)).

4 In addition, the 1982 Guidelines introduced the Herfindahl-Hirschman Index (HHI) measure of concentration. The drafter of the Guidelines (Baxter 1983) and economic commentary on them (Ordover and Willig 1983) defended its use primarily with reference to the relationship between the HHI and the likelihood of effective collusion identified by Stigler (1964). While both also noted that that HHI could also be related to the industry profit margins in a static oligopoly model, the 1982 Guidelines did not discuss either the possibility of non-zero conjectural variation or what were later termed unilateral effects.
} 
Coordinated effects were associated with oligopoly supergames, while unilateral effects were tied primarily to static Nash oligopoly models (Bertrand or Cournot) (Willig 1991). ${ }^{5}$

Building on the 1982 Guidelines, this approach recognized that a tacit but purposive "anticompetitive minuet" (to quote the 1993 Supreme Court in Brooke Group) could lead to a coordinated outcome in an oligopoly supergame without express collusion. But it did not broaden its understanding of coordination so far as to reincorporate oligopoly conduct predicated on natural and predictable rival reactions, which had been central in 1968. That type of conduct fell between the modeling cracks. ${ }^{6}$ It does not occur in static Nash equilibrium (where by definition conjectural variations are zero). And although it, like a wide range of other conduct, can in principle be brought into the oligopoly supergame framework, that framework directs attention to the purposively collusive (express or tacit) possibilities. ${ }^{7}$

The 2010 Horizontal Merger Guidelines reincorporate the dormant but still vital idea that a softening of competition-yielding supracompetitive oligopoly pricescan result from the natural and predictable reactions of rivals. ${ }^{8}$ These Guidelines describe "coordinated effects" as adverse competitive effects arising from "coordinated, accommodating, or interdependent behavior among rivals," which can involve "parallel accommodating conduct" that is not pursuant to a prior understanding and does not involve reactions intended to punish cheating, but that "nevertheless emboldens price increases and weakens competitive incentives to reduce prices or offer customers better terms." Thus, they bring back a recognition that coordination can emerge from non-purposive "interdependent behavior." While this older idea was once central to both industrial organization economics and antitrust, it has been marginalized by both disciplines.

We aim to show why the 2010 Merger Guidelines were right to reincorporate this older idea, and to suggest a corresponding research agenda for antitrust economists and lawyers.

The Guidelines do not provide much guidance on evaluating whether a merger creates parallel accommodating conduct—nor could they be expected to do so given the way that earlier Guidelines and the economic literature has developed. Our goal in this paper is to begin the work of rehabilitating the significance for antitrust enforcement-particularly horizontal merger analysis—of coordinated conduct in

\footnotetext{
${ }^{5}$ One of us (Baker) worked on the drafting of the 1992 Guidelines.

${ }^{6}$ Theoretical research on conjectural variations did not stop with the game theory revolution in microeconomics. In particular researchers have proposed ways to pin down the degree of conjectural variation that is most consistent with various theoretical approaches: e.g., Bresnahan (1981), Daughety (1985), Dixon and Somma (2002), Dockner (1992), Friedman and Mazzetti (2002), Lindh (1992), Liu et al. (2007), Maskin and Tirole (1987), Perry (1982), Possajennikov (2015). Researchers have also analyzed various effects of conjectural variation on competition (e.g., Ordover et al. 1982, pp. 1869-71, analyze the consequences for the aggregate industry markup of a merger-related shift from zero conjectural variations to non-zero conjectural variations). But that literature has not yet generated a simple, defensible workhorse model comparable to the models that underlay the competitive effects analyses that were described in the 1992 and 2010 Horizontal Merger Guidelines.

${ }^{7}$ See note 13 below.

${ }^{8}$ One of us (Farrell) worked on the drafting of the 2010 Guidelines.
} 
the gap between static Nash equilibrium models and oligopoly supergame models. We explain the strengths and limitations of the oligopoly supergame framework for horizontal merger enforcement. We also take steps toward explaining, in terms of modern economic theory, how to reincorporate the missing role of natural and predictable reactions of oligopolists.

While "coordinated" effects have long been a central concept in the Merger Guidelines, the meaning of the term has varied over time as the focus of economic theory has changed. ${ }^{9}$ For that reason, we begin by explaining how we use the term; we highlight the distinction between coordinated and unilateral competitive effects.

It is linguistically natural to describe explicit collusion as involving "coordination" on an anticompetitive scheme and on plans to respond or "punish" a participant that "defects" from the scheme-thereby "deterring" such defections. The same language readily extends to incorporate "tacit... collusion [that] may or may not be lawful in and of itself”' (1992 Guidelines $§ 2.1$ ), and the 2010 Guidelines ( $\$ 7)$ similarly include "a similar common understanding that is not explicitly negotiated but would be enforced by the detection and punishment of deviations that would undermine the coordinated interaction."

From an economic point of view, the key issue is rivals' responses to a firm's competitive moves-most saliently, whether those responses discourage price cuts (and other pro-consumer changes). But the 1984 and 1992 Guidelines described "coordination" only in terms suggesting what we call "purposive coordination" (Baker and Farrell 2020).

In purposive coordination, responses are understood as the carrying out of what Schelling (1960) called "threats": responses that would not naturally be in the threatener's interest to carry out, had it not made the threat. ${ }^{10}$ The firms' goal-itself a purposive word-is to establish incentives to support as an equilibrium a predefined desired (anticompetitively profitable) equilibrium path. As the folk theorems in repeated games make clear, it is often possible for collusive pricing or output to be a subgame-perfect equilibrium if "supported by" sufficiently vigorous responses that deter more-competitive market choices. These responses are usually thought of as: (a) based on history (in particular, whether anyone has "cheated" and if so, perhaps who); and (b) discontinuous (any defection "triggers" strong retaliation). Such reactions require some sort of mutual understanding and detection and punishment of deviations. We discuss the workhorse model of purposive coordination-repeated games with Nash reversion-in Sect. 2.

\footnotetext{
9 Moreover, widely used economic concepts and closely related antitrust law concepts—such as "coordination," "agreement," "tacit collusion," "oligopoly interdependence" and "conscious parallelism"—do not have clear, established definitions in the industrial organization economics and antitrust policy literatures. For two efforts to define terms, especially "agreement," see Baker (1996) and Kaplow (2013).

10 Schelling distinguishes "threats" from "warnings." Both are communications that are aimed at shaping the responses of others. A warning describes what the speaker would do anyway. A threat communicates a commitment to do something that would otherwise not be in the speaker's interest. We identify warnings with natural and predictable (non-purposive) responses and threats with credible commitments to a (purposive) punishment response.
} 
As the game theory revolution taught us - and as Harrington (2014) has ably exposited in the coordinated effect context-all oligopoly dynamics presumably must be consistent with subgame-perfect equilibria, and "natural" dynamics are not an exception. One might naturally have hoped that characterizing the set of subgame-perfect equilibria is a good way to understand such dynamics. That hope has turned out to be largely unfulfilled: There are too many subgame-perfect equilibria for that characterization to be useful.

The folk theorems undertake that characterization and conclude that threats can "support" a wide range of behavior. With standard oligopoly stage-games and plausible discount factors, that wide range often includes fully collusive (shared monopoly) behavior even in unconcentrated industries (Shapiro 1989). Moreover, as a matter of game theory this is the case even if we limit attention to threats that are credible in the sense of subgame perfection.

Consequently, a focus on "what's the worst that can credibly happen?" - interpreting credibility in that sense-would suggest pervasive pessimism about oligopoly performance: One would expect most oligopolies to perform almost monopolistically. Moreover, since that pessimism applies pre- as well as post-merger, it militates toward fatalism about the competitive effects of a merger: If full collusion were very much in the cards with or without the merger, it's not clear that one should worry about mergers. And the theory offers no answers as to what degree of collusion is "very much in the cards" versus only a little so, or how a merger might affect that.

Finally, in light of those (well-known) facts, antitrust economists customarily pull back from attempts to apply the theory quantitatively, and that in turn weakens the impact of concerns about coordinated effects in a policy and litigation world that has (rightly or wrongly) become quantification-hungry.

Thus, at a high level, we propose stepping back and, while continuing to use insights from the folk theorems and the repeated game approach, refocusing attention away from "what's the worst that could happen (or the range of everything that could happen) consistent with subgame-perfect equilibrium?" and toward "what's natural and apt to happen?". That broadly was the goal of the conjectural variations approach, and it is our goal here. It is an ambitious goal, and we do not claim to accomplish it: We aim mostly to reinvigorate the question, and to suggest a navigable way forward.

While the analysis of "coordinated effects" has suffered from the problems just described, antitrust economics in practice has come to define the "unilateral effects" of a merger as changes in how each firm behaves if it maximizes profits on the assumption that its choices (of price, quantity, capacity, quality, etc.) do not affect its rivals' choices. In modern economic terms this typically means analyzing the static Nash equilibria of the oligopoly game: assuming zero conjectural variations.

These usages, taken together, on their face describe only some oligopoly conduct. They omit—or at least direct attention away from-conduct that is significantly driven by (a firm's expectations of) how rivals will respond, but that is "individually rational, and not motivated by retaliation or deterrence nor intended to sustain an agreed-upon market outcome" (2010 Guidelines § 7). We have in mind natural and predictable business responses of firms to their rivals' price changes (or other 
competitive conduct). When competition is softened as a result, we term those oligopoly outcomes "non-purposive" coordination. Non-purposive coordination may be contrasted with the outcomes of static Nash equilibrium models in which firms are assumed not to respond to their rivals. A more subtle contrast is with the purposive coordination that arises when firm responses are part of a scheme or attempt to develop a consensus or deter price-cutting.

To clarify the distinction we make between non-purposive and purposive conduct, consider the different ways thinking that would be involved ${ }^{11}$ : Suppose that a firm's executives say that if they lower price, they expect their rivals to lower prices in response-and that this expectation discourages them from cutting price. If the executives expect rivals to match because they are trying to make price-cutting less profitable for the first firm, they are thinking in terms of purposive conduct: about deterrence of cheating. If the executives expect rivals to match simply because the rivals would lose too many customers if they kept their prices high, they are thinking in terms of non-purposive conduct: about natural and predicable reactions.

Or suppose a firm's executives routinely match when rival firms cut prices. If the executives say "we want to send a signal that we would like to avoid a price war," or "our policy is to always match rivals' prices, even if it might not always seem to make business sense, so that rivals will know they can't profit from price-cutting", they are thinking in terms of purposive conduct. If they say "we see that the overall industry price level has declined, and will lose many customers unless we reduce price in response", they are thinking in terms of natural or non-purposive reactions.

We do not grapple with the empirical challenges that arise in identifying the natural and predictable reactions of firms to changes in the decision variables of rivals. Such reactions must be distinguished from the consequences of common shocks (observed by multiple rivals but not by the econometrician) or of rivals' learning about industry costs and demand by observing changing market prices. Empirical identification problems are compounded because the number of potentially distinct interfirm reactions grows much more rapidly than the number of firms that interact. We also do not grapple with the problem of mapping responses that are observed in data to an underlying theoretical model (Corts 1999). ${ }^{12}$

As we explore in Sects. 3 and 4 below, non-purposive coordination includes cases in which a "leader" sets a price and one or more rivals then respond based

\footnotetext{
11 We do not mean to suggest that courts look solely or even primarily to intent evidence to distinguish between purposive and non-purposive conduct. Rather, we are describing hypothetical states of mind as an aid to understanding.

12 Nor do we grapple with the challenge of classifying experimental or empirical examples of algorithmic coordination as purposive or non-purposive. In one prominent experimental study, supracompetitive prices emerged when firms set price through algorithms that used trial-and-error with machine learning to work out strategies, but did not otherwise communicate (Calvano et al. 2020). While the authors interpret their results through a purposive (repeated game) lens, the gradual transition they observe as the firms return to supracompetitive prices after they match an initial price cut induced exogenously differs from the highly non-linear transitions between states of play often stressed in studies of supergame models. On the other hand, our "Appendix" provides an example in which non-purposive coordination leads to gradual transitions.
} 
on short-run incentives given the leader's choice. ${ }^{13}$ This in turn would include the Stackelberg model of duopoly or oligopoly, and also the dominant firm/competitive fringe model. The same spirit infuses longer-run incentives that flow from Stackelberg-type Markov reactions in Cyert and DeGroot (1970) and Maskin and Tirole (1987), which are not leader-follower models. In Schelling's terminology, firms' responses in such models correspond to "warnings," not "threats," because they reflect the responding parties' underlying natural incentives-not a bootstrapped equilibrium.

While oligopolists sometimes collude or perform an "anticompetitive minuet" to train one another not to cut prices, such purposive dynamics are surely by no means the only kind of reactions observed among oligopolists. Often firm A will change its price or output decisions simply because a rival firm B has done so, which alters the market environment that faces A. After all, a change in B's price shifts A's residual demand curve, which would be expected to make a different choice optimal for A even if A is in no way trying to reach and support a favored equilibrium or to "deter" B from changing its price or "retaliate" for its having done so. This is the essence of Turner's observation that firms will "inevitably react" to their rivals' price cuts, and it is analyzed in Sects. 3 and 4 below. Indeed, firms' tracking and responding to rivals' moves is often seen as a hallmark of who significantly competes with whom: responding to rivals' moves and taking account of rivals' likely responses is ubiquitous in oligopoly. Not all such oligopolies are attempting to collude.

We seek to avoid turning this discussion into one about terminology or classification. One could classify oligopoly outcomes that arise from natural and predictable responses under either the "unilateral" or the "coordinated" heading. The 2010 Guidelines place "parallel accommodating conduct" under the "coordinated" heading because it centers on rivals' responses, and we follow that choice here and in our earlier (Baker and Farrell 2020) work. Even if one might defensibly classify this conduct under the "unilateral" framework, in practice the modern antitrust economics of "unilateral effects" overwhelmingly assumes simultaneous-move Nash equilibrium in actions such as prices or quantities, and leaves out conduct that is predicated on non-zero conjectural variations. But we stress that our point is to prevent economically significant effects from falling through modeling or classification cracks-not to quarrel about classification decisions. ${ }^{14}$

\footnotetext{
${ }^{13}$ To model coordination in the framework of purposive deterrence and threats, it is technically unnecessary to have firm 1's price at time $t$ interact in the market with firm 2's price at time $(t+1)$. For instance, the two prices need not both be available to any specific customer. Consequently, if researchers happened to approach the problem from the perspective of purposive deterrence, or if they were seeking simple models of coordination without aiming to include all kinds, it would be a natural modeling simplification to suppose that each period is structurally independent of history - as the standard repeated game literature does in fact suppose. But, as Maskin and Tirole (1988) discuss, that modeling simplification eliminates any price commitment that can be naturally reacted to. It rules out—presumably inadvertently - the kinds of natural or Markov responses that are studied by Cyert-March, Maskin-Tirole, and here. See also Fudenberg and Tirole (1991, ch. 13).

${ }^{14}$ If "coordination" is limited (by definition) to purposively collusive outcomes, as was the focus of the 1992 Guidelines, then all other oligopoly conduct—including parallel accommodating conduct—would be classified as unilateral (absent some third category). If so, the 2010 Guidelines, which we follow, would be understood as changing the way that parallel accommodating conduct is classified. In any
} 
In Sect. 2 below, we discuss the repeated game approach to coordinated effects, which has dominated the economics discussion of the topic in recent decades. We stress that it is best understood as identifying outer bounds on coordinated effectswhat is the worst that might happen?-rather than predicting what is apt to happen. We offer some suggestions for how the theory might be made more helpful for analyzing mergers and quantifying their adverse effects by relaxing some extreme assumptions.

We then consider ways to broaden the understanding of coordination by discussing the economics of "parallel accommodating conduct," which we identify with "natural" ("warning"-like or "non-purposive") oligopoly responses-in contrast to those that are often studied in the repeated game framework, which have a constructed and purposive ("threat"-like) flavor. ${ }^{15}$ This arguably takes us into modeling conjectural variations, which was once an important topic in industrial economics but has languished. The conjectural variations approach to oligopoly analysis focuses on how the strength of responses affects conduct and performance-though the strength of those responses were often left un-modeled, which made that approach incomplete.

One reason, we suspect, that the work on oligopoly behavior in Markov equilibrium models by Nobel laureates Maskin and Tirole has not generated more of an economics literature is that it is technically difficult even in the simplest cases. Maskin and Tirole (1987) themselves solve only a symmetric linear duopoly case, and even then a quartic equation is required. Below, we propose a way to make some more tractable progress. Specifically, in Sect. 3 we propose that studying Stackelberg responses-which are the epitome of "natural" in their very simple dynamic context, and the starting point of the Cyert-DeGroot and Maskin-Tirole modelsmay offer a path to sensible calibration of natural and predictable responses in a more complex dynamic environment. For that reason, in Sects. 3 and 4 we consider models with Stackelberg reactions, and in particular compare those to Nash equilibrium models.

In Sect. 3, we link the incentive effects of Stackelberg responses to the familiar antitrust concept of diversion ratios: We find, in a simple case, that the effect on firm 1's pricing incentives of anticipating a Stackelberg response by firm 2 can be quantified as half the product of the diversion ratios between the two. In some variants of the Stackelberg framework we calculate the price effects of simple three-totwo mergers and compare those effects to those calculated in the standard unilateral Nash-Bertrand framework. In those calculations, which will be set forth in Sect. 4, prices are higher than in the conventional unilateral effect analysis-both pre- and

\footnotetext{
Footnote 14 (continued)

event, the important point is not the classification rubric, but rather that the 2010 Guidelines highlight the significance of that form of oligopoly behavior and seek to ensure that it does not continue to fall through the cracks.

15 Moresi et al. (2015) propose an alternative interpretation of "parallel accommodating conduct" that treats it as purposive. In their model, price-matching is a mechanism by which firms identify and reach a consensus coordinated price, and deviation from that outcome is deterred by rapid detection and response.
} 
post-merger - and the competitive effects of mergers are also larger. While the latter results in particular may well not be general, they point to the potential for significant errors if the Nash-Bertrand model is used to estimate merger price effects when parallel accommodating conduct is present.

The "Appendix" presents numerical simulations of a simple behavioral model in which firms take turns setting price to match the average of other firms' prices. While we do not derive that behavior from an optimizing model, similar responses could be natural and predictable under some circumstances. For instance, in the optimizing model of Sect. 4, each Stackelberg follower goes part-way toward matching its rivals' average price.

Starting from a uniform (and therefore steady-state) market price, the model that is set forth in the "Appendix" envisions firm 1 perturbing that steady state by raising its price on day 1 , thereafter reverting to turn-by-turn matching. We numerically calculate the new (higher) steady-state price to which the dynamic system converges, and quantify the tradeoff for firm 1 between raising the steady-state price on the one hand, and avoiding losing customers to an interim pricing disadvantage on the other hand. We illustratively study how that tradeoff is affected by the number of (symmetric) firms and by a merger between two such firms.

As with the Stackelberg models that we explore in the text, this model displays how horizontal mergers can raise price through effects on rivals' reactions, in ways that are assumed away in Nash models and are not salient (even if technically present, at least potentially) in standard models of oligopoly supergames.

Our modeling here is exploratory and aims at setting forth a research agenda to reanimate analysis of the coordinated effects analysis of mergers: the topic of Sect. 7 in the 2010 Guidelines. We first suggest some directions in which the repeated games approach to coordinated effects can be made more realistic: a precondition for useful quantification. We then begin the work of reincorporating into competitive effects analysis important ideas that have fallen dormant in antitrust economics about the role of natural and predictable reactions of oligopolists, which is our interpretation of the Guidelines' discussion of parallel accommodating conduct. Throughout, we identify a number of open questions.

\section{Repeated Game with Nash Reversion}

This section describes what is widely viewed as the workhorse economic theory model for coordinated oligopoly conduct, and thus for evaluating the risks of coordinated effects from a merger: This is an oligopoly supergame that consists of repeating a static stage game, and in which supracompetitive prices are supported by the threat of reversion to static Nash pricing. Because this model naturally incorporates ideas of defection, detection, and punishment, economists tend to identify it (or supergame models more generally, which allow for the possibility of non-Nash reversion) with what we call "purposive" coordination.

Our exposition emphasizes problems with this model and-consistent with our general approach of setting forth a research agenda-suggests a route for addressing them. The central difficulty is that the model does not predict the extent of 
cooperation with precision. After all, the fundamental ("folk") theorem in this literature is that the threat of reversion can support a very wide range of subgame perfect equilibria. That theoretical unpredictability was echoed in the 1992 Merger Guidelines, which first identified coordination with the oligopoly supergames. Those Guidelines (\$ 2.1) noted "the difficulties of predicting likely future behavior based on the types of incomplete and sometimes contradictory information typically generated in merger investigations."

More pointedly, the 2010 Guidelines (§ 7.1) warn that "the risk that a merger will induce adverse coordinated effects may not be susceptible to quantification or detailed proof." Not surprisingly, the 2010 Guidelines go on to say that "the Agencies may challenge mergers that in their judgment pose a real danger of harm through coordinated effects, even without specific evidence showing precisely how the coordination likely would take place."16 (By comparison with the unpredictable outcomes in this model, the natural reactions we identify with non-purposive coordination and model in later sections of our paper, and the equilibria that flow from them, are in principle substantially more predictable.)

To address this problem, researchers typically adopt a refinement to the model to limit the range of possible outcomes. Yet some approaches to doing so-notably selecting the most collusive outcome among those possible-yield wildly unrealistic predictions when the model is calibrated. Our exposition suggests in particular that predictions could be made more realistic by incorporating the possibility that the transition between collusive and competitive states is not deterministic but occurs with probability.

The model supposes that a fixed set of firms repeat a simultaneous-move stage game for an indefinite number of times, with a discount factor per period of $\delta<1$. ${ }^{17}$ It is simplest to go directly to describing the candidate equilibrium studied. Each firm plays a simple history-dependent strategy, which is centered on a specified "cooperative" action for each firm in the stage game. The strategy is: If every other firm has played its cooperative action in every period so far, play your cooperative strategy; if not, play your one-shot Nash strategy. This is often referred to as cooperation with the (perhaps extreme) threat of permanent "reversion" to one-shot Nash; this is sometimes called a grim trigger strategy. Attention centers on whether that threat is severe enough to deter opportunism.

This model has more than one interpretation.

\footnotetext{
${ }^{16}$ By contrast, the 2010 Guidelines ( $\$ 6.1$ ) explicitly allow for quantification when discussing unilateral effects, observing that "the Agencies may construct economic models designed to quantify the unilateral price effects resulting from the merger." The precision of models of unilateral effects-and the concomitant way that they make transparent the mechanism by which the merger harms competition-help explain why unilateral effects models have become more important in horizontal merger analysis over time. Baker (2003).

17 An "indefinite number of times" may well be finite but uncertain, as long as it is never common knowledge that (for a finite $T^{*}$ ) the game will conclude within the next $T^{*}$ periods. For example, there may be a constant hazard rate of unexpected termination, which would go into $\delta$. With ongoing market growth as well as time discounting, one might have $\delta \geq 1$, but presumably not forever, and we follow most of the literature in ignoring this possibility here.
} 
- One interpretation aims to describe how an oligopoly might actually behave when "trust" can develop among oligopolists and they perceive that failing to cooperate will destroy that trust and will in fact lead to one-shot Nash behavior.

- Less formal discussions of oligopoly sometimes suggest that while some concentrated industries might behave "competitively" (i.e., imperfectly competitively, as for instance Cournot or differentiated Bertrand), others might attempt to implement as much cooperation as incentives allowed them to sustain. Neither pattern of conduct is fully competitive, and neither may implement full monopoly; but a switch between those models would be important.

- Another interpretation aims to describe the enforcement workings of a cartel (whether or not explicit or illegal) that uses reversion to Nash behavior as a planned punishment scheme. These are not the "optimal punishments" that are employed in modern game theory, and they are implicitly limited by inability to use side payments, but they are often ample to sustain full or substantial collusion.

- This interpretation views the coordination and responses as designed with a goal in mind. In Baker and Farrell (2020) we described this as "purposive coordination."

- A third sees the model in a mechanism-design spirit as (partially) characterizing subgame-perfect cooperation (the equilibrium path), which includes describing certain off-equilibrium behavior that could sustain it—which is not necessarily the off-equilibrium behavior that does sustain it: Although cooperation might be supported through entirely different responses-e.g., price-matching-the folk theorems tell us that what can be sustained with any subgame-perfect responses (including price-matching) can also be sustained using optimal punishments, or (if the equilibrium path strictly dominates Nash) using Nash reversion. In this interpretation, an equilibrium with Nash reversion is treated as a proof that a certain cooperative path can be sustained-not as a description of what would actually happen if a defection occurred.

- As strict game theory, the model offers only outer bounds (which are often loose) to a plethora of equilibria. However, it is sometimes (explicitly or implicitly) made more narrowly predictive by adding an "equilibrium selection" condition that cooperation would be at the maximum that is consistent with incentives, or at least that special attention should be paid to those most-cooperative equilibria. This addition arguably makes the most sense in interpretations that are the most purposive.

- If the industry maximizes cooperation subject to incentive constraints, either no incentive constraint binds (so full cooperation is compatible with incentives and thus under this interpretation will prevail), or at least one constraint binds. In the latter case we can describe a firm whose incentive constraint binds as a "maverick."

In the candidate equilibrium the industry can be in either of two states: cooperative or competitive. All players know which state the industry is in. As there are no physical state variables, these states are entirely a matter of expectations: 
- When the industry is in the "competitive" state, each firm expects all others to play the one-shot Nash move (e.g., price). In what we will call the extreme version of the model, the competitive state, once reached, persists forever.

- When the industry is in the "cooperative" state, each firm expects all others to play a known cooperative move (e.g., a higher price or lower output than the one-shot Nash move). In the extreme version of the model, play begins in the cooperative state, which lasts until someone fails to play its cooperative move and then transitions permanently to the competitive state.

Below, we allow for more general transition probabilities between the two states than does the extreme version of the model. This appears more realistic in descriptive interpretations of the model - and more robust or prudent in design interpretations. It also can help address the troubling fact that the extreme version often drastically over-predicts cooperation.

If all firms play the cooperative move, each firm's profits are higher than in the Nash outcome. For each firm, however, the cooperative move is not a short-run best response to all others' playing the cooperative move. This creates a short-run incentive to "cheat" in the cooperative state; but there is a longer-run incentive to protect that lucrative state.

The analysis then asks when it is a subgame-perfect equilibrium for everyone to play this strategy. Because subgame perfection is obviously the case in the competitive state, the question boils down to whether the prospect of transition to the competitive state-reversion to one-shot Nash play-is a harsh enough threat to deter "cheating" in the cooperative state. ${ }^{18}$

For a given firm, write $\mathrm{n}$ for its Nash stage-game payoff, c for its stage-game payoff if it and everyone else cooperates, and $b$ for its stage-game best-response payoff if everyone else cooperates. Then $b>c>n$. For that firm, write $\mathrm{U}$ and $\mathrm{V}$ for its continuation present-value payoffs in the competitive and cooperative states, respectively, with assumption (here purely as a matter of notation, which will be substantively evaluated below) that it and all other firms cooperate in the cooperative state. ${ }^{19} \mathrm{We}$ anticipate that $V>U$ and that the firm may cooperate in the cooperative state (accepting c rather than $\mathrm{b}$ in the short run) in order to make it more likely that they will get $\mathrm{V}$ rather than $\mathrm{U}$ in future. In the extreme version of the model "more likely" means certain versus impossible, but we make it more generally stochastic. ${ }^{20}$ All these payoffs are firm-specific.

\footnotetext{
18 Other continuations that follow defection from the cooperative equilibrium path-and in particular the "optimal punishment" schemes-require incentive-compatibility constraints during the punishment phase as well as on the equilibrium path. For simplicity, and because it is the norm in antitrust economics, we focus on Nash reversion.

19 The cooperative actions need not achieve full shared monopoly. Empirically, even in explicit cartels they often do not, and in general stopping short of full shared monopoly can facilitate coordination by relaxing the incentive constraint (although it does not do so in the simple undifferentiated Bertrand case).

${ }^{20}$ As far as we know this approach of working with reduced-form transition probabilities is new; but the intuitive lessons are well understood, and a more specialized model with explicit (cartel design) micro-foundations for those probabilities was analyzed by Green and Porter (1984), see also Abreu et al. (1991). Perhaps confusingly, these models (or equilibria) are intuitively Markov-like, in that transition probabilities between the states are stochastically governed by current state and current conduct in a way that does not depend on time or on previous history except, importantly, that the "state" itself summa-
} 
In a cooperative period, if the firm plays the cooperative move, it perceives that there is a probability $\mathrm{p}$ of transition to the competitive state, and this rises to $r$ if it "cheats". In a competitive period there is a probability q of transition to cooperative; for simplicity we assume that $\mathrm{q}$ is unaffected by conduct. The extreme version further assumes $p=0=q$ and $r=1$; we solve the more general case, which we think is more realistic and more compelling.

- Assuming that $p=0$ amounts to assuming that if this firm does not cheat this period, no firm does and no firm is mistakenly perceived to have cheated (broadly including the possibility that a firm changes its strategy for other reasons such as new management or a technological transition). A positive value of $p$ accounts for the possibility of a false positive (the firms revert to competition after a mistaken diagnosis of cheating, as in Green and Porter 1984), or that one of this firm's rivals cheats or changes its strategy and is "detected". ${ }^{21}$

- Assuming that $r=1$ amounts to assuming that if this firm does cheat, it will precipitate immediate transition to competition for sure; assuming $r<1$ accounts for possible failure to detect the cheating, or caution or reluctance in abandoning the lucrative coordination if it is possible to turn a blind eye to what might be inconclusive evidence of cheating.

- Assuming that $q=0$ amounts to assuming that there can never be exit from the competitive state; assuming $q>0$ accounts for the possibility of forgiveness, forgetfulness, or renegotiation. While the literature on renegotiation in repeated games predominantly looks for equilibria in which no joint temptation to renegotiate arises (e.g. Bernheim and Ray 1989; Farrell and Maskin 1989), it shares with our approach here the spirit that a jointly tempting renegotiation should not simply be ruled out.

To analyze the firm's incentives, consider the following. In the competitive state, the firm's expected value from competing is:

$$
U=n+\delta(q V+(1-q) U) .
$$

In the cooperative state, the firm's expected value from cooperating is:

$$
V=c+\delta(p U+(1-p) V) .
$$

To solve Eqs. $(2.1,2.2)$ for $[V-U]$, rewrite them as:

\footnotetext{
Footnote 20 (continued)

rizes a key aspect of the history of play. Maskin and Tirole (2001) discuss what should be regarded as Markov in such contexts.

21 Levenstein and Suslow (2006, pp. 75-79) find that in their sample of express cartels (including some that are legal), the colluding firms commonly develop organizational methods to detect and deter cheating but cartels commonly break down when some members wish to renegotiate the terms of the coordinated outcome following unexpected shocks to demand or other forms of instability in the economic environment, or from the inability of the cartel to deter or accommodate entry. These observations suggest that cartels can break down for reasons other than the simple choice to cheat that is featured in the standard model; this can be recognized within our framework if we assume $p>0$.
} 


$$
\begin{aligned}
& (1-\delta) U=n+\delta q(V-U) \\
& (1-\delta) V=c-\delta p(V-U)
\end{aligned}
$$

Subtracting the first from the second,

$$
(1-\delta)(V-U)=c-n-\delta(p+q)(V-U) .
$$

Hence,

$$
(1-\delta+\delta(p+q))(V-U)=c-n
$$

As noted above, we must check whether it is rational for the firm to cooperate in the cooperative state. We can write its expected value from a one-time deviation starting in the cooperative state as:

$$
W=b+\delta(r U+(1-r) V) .
$$

Incentive compatibility is the condition that $W \leq V$, or:

$$
c+\delta(p U+(1-p) V) \geq b+\delta(r U+(1-r) V) .
$$

We eliminate $U$ and $V$ from condition (2.5) using Eq. (2.3), which yields:

$$
b-c \leq \delta(r-p)(V-U)=\frac{\delta(r-p)}{1-\delta+\delta(p+q)}[c-n] .
$$

Equivalently,

$$
S \equiv \frac{b-c}{c-n} \leq T \equiv \frac{\delta(r-p)}{1-\delta+\delta(p+q)}
$$

Condition (2.6) is the incentive compatibility condition for this firm to go along with the candidate equilibrium. This is a necessary and sufficient condition for the specified degree/form of cooperation-each firm playing its cooperative move- to be the equilibrium path of a subgame-perfect equilibrium.

It may be helpful to rewrite $S$ to stress that only payoff ratios matter:

$$
S=\frac{\left(\frac{b}{c}\right)-1}{1-\left(\frac{n}{c}\right)} .
$$

Observe that (2.6) separates stage-game payoff information (left-hand side, $S$ ) from information about discounting and state-transition dynamics (right-hand side, $T)$. This specification generalizes the standard model, which is the special case $p=0=q, r=1$ and which thus turns (2.6) into:

$$
S=\frac{b-c}{c-n} \leq T=\frac{\delta}{1-\delta} .
$$


In either (2.6) or the extreme case (2.8), we can analyze $S$ and $T$ for a particular firm or market, and for a particular form and degree of cooperation that leads to the payoffs $c$ and $b$ (relative to $n$ ). Carl Shapiro calls $S$ the firm's "Disruption Index" and proposes evaluating it quantitatively as a way to gauge the relative coordination incentives of rival firms or how those incentives change with a merger. ${ }^{22}$ This strategy would make sense, for instance, if $T$ is relatively constant but hard to quantify.

\subsection{Determinants of $S$}

$S$ depends on the stage game and degree/form of cooperation, in ways that are widely explored in the economics literature. ${ }^{23}$ An extreme example that is often found in textbook treatments (e.g., Tirole 1989) is undifferentiated Bertrand competition with constant and symmetric unit costs. Then $n=0$; and if cooperation involves all firms' setting the same above-cost price and sharing industry profits of $\pi$-with a specific firm getting a share $s$ of those profits - then for that firm, $c=s \pi$ and $b=\pi$. Consequently $S=(1-s) / s$; and thus (2.8) translates to $s \geq 1 /(1+T)$. For this to be true for all firms implies high concentration unless $T$ is large. At the firm level, the firm with the smallest market share (other things equal) most constrains cooperation, because it has the least stake in the cooperative outcome and the most to gain from deviation (its value of $c$ and hence of $(c-n)$ is smallest, while its value of $(b-c)$ is largest). While the equation $S=(1-s) / s$ depends on the specifics of that stage game, it is more robust that a firm's incentives will more easily satisfy the incentive compatibility condition (2.6) if it has a relatively large stake in the success of coordination, relative to its short-run temptation to "cheat."

When the stage game is undifferentiated Bertrand, if any coordination is sustainable, then so is coordination on full shared monopoly. In general, though, that is not the case, and (2.6) or (2.8) often becomes harder to satisfy the closer the cooperative conduct is to full shared monopoly. Then it can well be that some coordination, but not full shared monopoly, is feasible; and coordination is limited by one or more "maverick" firms with $S=T$ while other participants have $S<T .{ }^{24}$ In interpretations of the model that put particular weight on the maximum sustainable coordination (e.g., Baker 2010), shifts in incentives for those mavericks are predictors of effects; and in particular shifts that are caused by merger are predictors of coordinated effects of the merger. For a given value of $T$, if the highest value of $S$ among participants in coordination falls, additional coordination becomes easier to sustain.

As a starting point for analyzing shifts in $S$ that are due to merger, observe that absent efficiencies, for a given on-path cooperative action profile, the merged firm's

\footnotetext{
22 Shapiro described this analysis in his trial testimony as an expert on behalf of the plaintiff states in New York v. Deutsche Telekom AG, 439 F.Supp.3d 179 (S.D.N.Y. 2020).

23 Analyses of the stage game, and in particular of S, have considered, for example, a Cournot competition stage-game, or firm-level capacity limits in the (otherwise) undifferentiated Bertrand stage game, or differentiation in the Bertrand stage game. For surveys, see Kühn (2004) and Porter (2020).

${ }^{24}$ Not all firms need to "participate" in coordination for it to have substantial effects. Participation has real meaning in an explicit cartel. On the other hand, with a mechanism-design focus we can analytically treat all firms as participants if we are willing to say that some participants are not constrained.
} 
stage-game payoff if all play that profile is simply the sum of the merging firms' cooperative stage-game payoffs: $c_{12}=c_{1}+c_{2}$. Here we use the notation that subscripts 1 and 2 refer to the pre-merger firms, and subscript 12 denotes the merged entity. If the same additivity were to hold for payoffs $n$ and $b$-that is, $n_{12}=n_{1}+n_{2}$, and $b_{12}=b_{1}+b_{2}$ - then we would have:

$$
S_{12}=\frac{\left(b_{1}+b_{2}\right)-\left(c_{1}+c_{2}\right)}{\left(c_{1}+c_{2}\right)-\left(n_{1}+n_{2}\right)}=\frac{c_{1}-n_{1}}{\left(c_{1}+c_{2}\right)-\left(n_{1}+n_{2}\right)} S_{1}+\frac{c_{2}-n_{2}}{\left(c_{1}+c_{2}\right)-\left(n_{1}+n_{2}\right)} S_{2} .
$$

This is a weighted average of $S_{1}$ and $S_{2}$, and hence in particular it is lower than the maximum of $S_{1}$ and $S_{2}$. Moreover, observe that $\mathrm{S}$ is increasing in $b$ and $n$, and decreasing in $c$. Hence a sufficient (not necessary) condition for the merged firm's $S_{12}$ to be lower than the maximum of the pre-merger $S$ 's is that $b$ and $n$ are sub-additive and $c$ is super-additive: $b_{12} \leq b_{1}+b_{2}$, etc. While it remains an open research topic when that is the case, the broader point is that a merger that involves a maverick-a firm whose incentives are the binding constraint on coordination-and that leaves $T$ unchanged relaxes that constraint on coordination, which typically makes it easier to sustain additional coordination. In an interpretation of the model that puts significant weight on firms' achieving the maximum level of coordination sustainable using Nash reversion, the difference between $S_{12}$ and $\max \left[S_{1}, S_{2}\right]$ is related to the magnitude of this enhancement of coordination.

The indications above are qualitatively consistent with informal experience and with the treatment in the Guidelines that concentration matters for the sustainability of this form of coordination, including increases in concentration due to merger; that a small participant with less stake in the coordinated outcome (low share s), and/or the greatest ability to expand inexpensively, is most apt to be a maverick ${ }^{25}$; and that mergers that involve mavericks raise additional concerns about coordination.

\subsection{Determinants of $T$}

In the standard case (2.8), $T$ is solely a function of $\delta$. If we interpret $\delta$ as the perperiod discount factor that corresponds to the firm's incremental cost of capital, where a "period" is the length of time until rivals would respond to a competitive initiative such as a price change, we would often expect $\delta$ to be very close to 1 and accordingly $T$ to be large.

Qualitatively, the theory exposits how low interest rates and rapid responses by rivals can make short-run gains unimportant in present value compared to sustaining lucrative industry peace, and the Guidelines (7.2) discuss the relevance of rapid responses. However, as has been recognized at least since Shapiro (1989), in simple

\footnotetext{
25 A firm's $S$, and hence its incentive compatibility constraint, depends on both its stake in the coordinated outcome (which determines the numerator of $S$ ) and its ability to expand inexpensively (which determines the denominator of $S$ ). Among other things, this means that a firm with a small share might not be a maverick if it is very costly for the firm to expand. On methods of identifying mavericks empirically, see Baker (2002, pp. 173-77).
} 
models this qualitative assonance with common sense and experience falls apart when we put in some sensible numbers for $\delta$. For example, with $\delta=0.99$ - which with 21 st-century interest rates is by no means implausibly high if a "period" corresponds to the time lag for rival reactions-99 symmetric firms could fully collude in an undifferentiated Bertrand industry. Different but also highly alarming substitutions into (2.8) apply, e.g., in a Cournot industry.

This implausible observation seems at least detached from the Guidelines' thresholds and analysis.

If condition (2.8) (at shared monopoly pricing) were viewed as sufficient, as well as necessary, for full collusion to occur, it would seem to suggest little or no incremental prospects of coordination post-merger versus pre-merger because it would suggest full coordination even pre-merger, for many of the mergers at issue in modern antitrust practice.

On the other hand, if condition (2.8) is interpreted only as a necessary condition, it would often tell us only, uninformatively, that one necessary condition holds both pre- and post-merger.

One response is that $\delta$ can capture more than just the capital-market time value of money, ${ }^{26}$ and may well therefore take much lower values than the capital market would suggest. For example, as was noted above, it might incorporate a hazard rate of the game's coming to an end-perhaps a substantial hazard rate since "the game" can presumably end, or re-set, in multiple ways. ${ }^{27}$ Or it might reflect internal incentives for executives or salespeople who are rewarded based on short-run performance measures. Another response is that simplified calculations can understate $S$-although in (2.6) the only way that $S$ can be very large is if $c$ is not much above $n$. Here we focus primarily on relaxing the extreme assumptions on transition rates $(p, q, r)$ that translate (2.6) into (2.8). Doing so suggests that $T$ is likely considerably smaller (as well as more nuanced) than (2.8) suggests - especially for large discount factors. Returning to the more general (2.6) we rewrite $T$ :

$$
T \equiv \frac{r-p}{\frac{1-\delta}{\delta}+p+q} .
$$

From (2.10), using $0<\delta<1$, we have $T<\frac{r-p}{p+q}$. Here $(r-p)$ is the incremental probability of transition to the competitive state caused by cheating, and $(p+q)$ measures the impermanence of the states absent cheating. Thus, when $p$ and/or $q$ is nonzero, $T$ remains bounded from above as $\delta \rightarrow 1$, in contrast to its behavior in the simplified (2.8).

But why would $p$ and $q$ not be zero, or what determines their (and $r$ 's) magnitude? Here the discussion of what a cartel management might do, and the discussion

\footnotetext{
26 Abreu, Milgrom, and Pearce (1991) separate the effects of changes in interest rate, speed of observation, and speed of response-all of which are conflated in $\delta$.

27 If $q=0$, a hazard rate for breakdown of cooperation-here $p$-can be incorporated into $\delta$ in this way (one can mathematically normalize the Nash payoffs $\mathrm{n}$ to zero). With a nonzero $q$, it is less simple.
} 
of how trust might plausibly develop and erode among oligopolists without cartel management, are somewhat different.

- In this simplified (e.g., complete information) model, cartel management would want to make $p=0=q$ and $r=1$. However, this depends on strong assumptions about information and an assumption that firms-complex webs of self-interested and imperfectly rational agents-reliably pursue their economic interests as modeled. Green and Porter (1984) and Abreu et al. (1991) explore tradeoffs among $(p, q, r)$ when an optimizing cartel management is constrained by imperfect observability of actions.

- On the other hand, if we think of the reversion equilibrium as behavior towards which an industry might converge, rather than as a designed mechanism, then ( $p$, $q, r$ ) would presumably result from human dynamics of trust, distrust, renegotiation, denial, and revenge.

Either way, however, not only are the assumptions $p=0=q$ and $r=1$ each separately extreme and all pushing in the direction of easier satisfaction of (2.6), but they also are in tension with one another:

First, $p=0$ and $r=1$ are in tension because successful coordination is not robust to the introduction of the possibility that firms may make mistakes in evaluating the behavior of their rivals. These assumptions rule out all mistakes. Having $r=1$ means that any defection entirely ensures transition to the competitive state; the firms never fail to respond to cheating by rivals (either because they fail to detect it or because they choose to ignore it). And having $p=0$ means that firms never transition to the competitive state for any other reason: They never mistakenly conclude that rivals are cheating, and they rule out the possibility that any firm will have an exogenous reason to change its strategy.)

Introducing even a small possibility of mistakes about rival behavior or strategies makes it much harder to sustain coordination by many firms over a sustained period. To see why, suppose $r=1$; and, rather than assuming $p=0$, suppose that there are $N$ firms, each independently defecting (or being so diagnosed) only in extraordinary firm-specific circumstances with small probability $k$. Then starting in the cooperative state, the single-period probability of no transition is $(1-k)^{N}$, or $p=1-(1-k)^{N}$. Even for quite small (but nonzero) values of $k$, this expression grows rapidly with $N$, to the point where $T$ in (2.6) is substantially lower than $T$ in (2.8). For instance, with $k=0.05$ and $N=10$ we get (approximately) $p=0.4$. Plugging that, together with $q=0$ and $r=1$, into (2.6) or (2.10) gives a limiting value of $T$ as $\delta \rightarrow 1$ equal to $0.6 / 0.4=1.5$, which makes (2.6) clearly much more restrictive of the stage-game payoffs $(n, c, b)$ for large $\delta$ than is (2.8). Coordination may remain feasible, but only if each firm's stage-game payoffs fall in a substantially more narrow range.

Perhaps a broader perspective on, or expression of, this point is that the standard incentive calculation treats each participant as pivotal. Without that participant's obedient participation, the cartel breaks down (or less colorfully, the equilibrium transitions into competitive mode). But with multiple parties each truly pivotal in that sense, there is only one way that it can work and many ways that it can break. 
Second, with $q=0$ and $r=1$ any breakdown is permanent. While participants might resist immediate renegotiation back to the cooperative state, it may be hard to believe that they are able to find their way initially to cooperation but cannot find their way back once a breakdown occurs. One can imagine reasons why renegotiation post-cheating could be more difficult than initial negotiation post-merger, ${ }^{28}$ but when that is not plausible, then the extreme assumptions $q=0$ and $r=1$ are in tension.

\subsection{What to Make of All of This?}

We think condition (2.6) —as illuminated by sensible judgment about $p, q$, and $r$, as well as $\delta$-is likely to be more reliable and more useful than condition (2.8). Indeed, we suggest that the lack of realism of the latter condition is widely recognized in practice: In our experience versions of (2.8) are often written out but less often quantitatively relied on. Empirical research - both quantitative and qualitative-into transition probabilities is limited. (But see Genesove and Mullin 2001; Levenstein and Suslow 2006; Porter 1985).

Antitrust economists may apply versions of this analysis. For instance, they may consider the level of $S$ in a particular industry, perhaps in particular the firm-specific $S$ that applies to a firm that may be a maverick, and how it will be affected by a merger-particularly one that involves the maverick. While it is rare in our experience to follow through on the conventional extreme version of the model by also quantifying $T$, and while simple ways of doing so would often yield implausible predictions, quantifying $S$ and discussing how it may change with the merger may be a sensible approach to evaluating the applicability of this model more broadly understood. One could say that it amounts to treating $T$ as very imperfectly observable, ${ }^{29}$ because of the difficulty making inferences about firms' estimates of the transition probabilities, and benchmarking the "Disruption Index" $S$ against a fairly diffuse distribution of $T$.

To similar effect, as experience accumulates in evaluating $S$ across collusive/ cooperative, non-collusive, and borderline (e.g., intermittently) collusive industries, $S$ could be benchmarked against those values; doing so would be similar in spirit to what the Merger Guidelines do in benchmarking values of the post-merger HHI

\footnotetext{
${ }^{28}$ For example, once one firm cheats, its rivals may no longer trust it to cooperate in the future, which complicates renegotiation by making it necessary for the coordinating firms to develop different means of detecting and punishing deviation. Or suppose that in the coordinated arrangement, output shares are allocated in the same way as capacity shares: This is a possible focal rule for determining market shares among coordinating firms. Then firms would have an incentive to expand capacity in order to be awarded a higher market share. A maverick could place itself in a particularly strong bargaining position by doing so, as a higher capacity could threaten to tip its incentives.

from cooperation to cheating, and thus allow it to impose substantial costs on the other firms if they do not award it a higher market share. Under such circumstances, renegotiating firms - having learned about this difficulty - may need to work out a different way to allocate market shares. In the absence of express communication, that renegotiation may be more difficult than the initial negotiation.

29 In particular, it may be difficult for courts to quantify the determinants of $T$, particularly the discount factor.
} 
against concentration levels that are thought to raise concerns about coordinated effects.

If a particular firm is indifferent between cheating and cooperating pre-mergerand it is thereby a maverick that constrains more effective coordination among the firms in the market-then for it, $S=T$. That relationship may make it possible to make inferences about how the merger affects equilibrium outcomes by investigating how the maverick's value of $S$ will change with the merger, as is suggested by Eq. (2.9), on the assumption that $T$ does not change. Doing so will most likely require structural modeling of the determinants of firm payoffs in various states of the world. If the merged firm would have structural characteristics similar to that of a non-merging rival, it may be reasonable to assume that after the merger its $S$ will be similar to that of the rival.

It may be reasonable to suppose that $T$ does not change with the merger; but that assumption may not always be plausible. If the merger would be expected to make cheating more easily observable, for example, it could increase $r$ or $\delta$, which would increase $T$. Or if the reduction in the number of firms facilitates cooperation, that could increase $q$, which would reduce $T$.

Moreover, with $S$ known, the relationship $S=T$ constrains the relationship among the transition probabilities $p, q$, and $r$. If, for example, it is plausible that $p=q=0$, then $r$ may be inferred from an estimate of the maverick's value of $S$ and an estimate of $\delta$. Its plausibility, and thus the plausibility of the model, could potentially be evaluated by comparing it with empirical estimates of price war frequency (as in Porter 1985) or with qualitative information from non-maverick firms about the frequency of price wars. Or if a merger between non-mavericks is expected to alter the probability that cheating will be observed and punished, an estimate of how $r$ would change, and thus how $T$ would change, could permit a quantitative analysis of how the maverick would modify its price to maintain the relationship $S=T$-and thus permit a quantitative analysis of the consequences of a merger of non-mavericks for the coordinated outcome.

\section{Stackelberg Reactions}

We next consider coordinated conduct that arises from the natural and predictable reactions of oligopolists; we use the lens of Stackelberg reactions. These are the responses that maximize followers' short-term profits. ${ }^{30}$ We begin by explaining why we believe that this lens will prove illuminating.

Sometimes, of course, firms simply will behave in a leader-follower way. Then the Stackelberg reactions are simply and obviously what happens. But more

\footnotetext{
30 We call them "Stackelberg" reactions because Stackelberg's theory of oligopoly involves actual reactions of the type and magnitude studied here. Mathematically these are also sometimes called Nash bestresponse functions, but that phrase is confusing and potentially misleading because in the Nash analysis there are no responses. (The best- "response" functions are a mathematical tool to help calculate simultaneous-choice equilibria).
} 
broadly, we are putting forward a more ambitious suggestion: That studying Stackelberg reactions is a sensible starting point for understanding dynamic natural (e.g., Markov) reactions in more complex and back-and-forth behavior patterns. As with any simplified and tractable approach to a complex issue, it is unclear how one could prove that alignment short of fully solving the complex conjectural variations problem (which would make a simplified approach redundant); but we can explain why we think that adopting the approach is a reasonable way to make progress:

First, Stackelberg reactions are (by definition) myopic. Their myopia rules out all purposive considerations, such as "teaching" or rewarding or punishing a rival, as those considerations are future-oriented. Thus, Stackelberg reactions are inherently non-purposive. Oligopolists may well learn to shade those reactions to a degree; but the shaded version may well be related to the starting-point natural reactions. ${ }^{31}$ When there is no collusive-type agreement but an oligopolist understands that its rivals will "inevitably react" to its price cut, "because otherwise the price cut will make a substantial inroad on their sales" (Turner 1962), it is plausible that the pricecutting oligopolist, attempting to assess the magnitude of such inevitable reactions, would at least treat as a point of departure the possibility that its rivals will act in accordance with their myopic best-response functions (i.e., their Stackelberg reactions). ${ }^{32}$ Thus, we suppose myopia on the part of followers but limited foresight on the part of the leader.

More symmetrically, leading multi-period models of natural reactions can be viewed as building from Stackelberg reactions. In Cyert and de Groot (1970) and a 1980s series of papers by Maskin and Tirole (notably 1987), firms take turns changing decision variables, and each such choice is in force for two periods. As a result, each choice is (for its first period) a reaction to the rival's still-in-force previous choice, and (for its second period) a commitment to which the rival reacts. As Maskin and Tirole (1988, p. 553) put it, "Markov strategies seem at times to accord better with the customary conception of a reaction in the informal industrial organization literature than do, say, the reactions emphasized in the repeated game (or 'supergame') tradition."

Unfortunately, the analysis is mathematically challenging: Even in symmetric linear duopoly cases, Cyert and deGroot end up presenting their results numerically, and Maskin and Tirole characterize the equilibrium responsiveness as a solution to a quartic equation. Models that are so technically demanding even in that limited case

\footnotetext{
31 One analogy is with the economics/game theory of bargaining: That theory recognizes that at some point either party would genuinely choose to walk away. Actual disagreement payoffs are not the end of the analysis, however, because there is often an incentive to "pretend" that the walk-away point is closer than it actually is. That kind of exaggeration or shading doesn't make the true walk-away point irrelevant. In technical terms, the virtual type is closely related to the true type. See, e.g., Fudenberg and Tirole (1991, p. 287). Another analogy, perhaps closer to home, is with the direct unilateral effects of a horizontal merger on the merging parties' conduct. Direct effects will be modified in complex ways by interactions with (e.g.) non-merging rivals' conduct; but direct effects nevertheless provides a sensible and more tractable way to evaluate unilateral incentives when analyzing mergers.

32 Another plausible possibility is that the oligopolist anticipates a simple behavioral response in the spirit of price-matching. See Anderson (1984) for analysis of quick-response full matching. We study a less extreme multi-firm behavioral model along those lines in our "Appendix".
} 
are not well adapted to serve as workhorse models for merger analysis, and in our experience have not been used in that way.

But we can say that those models are founded on Stackelberg reactions. Cyert and deGroot analyze a finite-horizon case (without discounting), where all the dynamics are built recursively on last-period Stackelberg responses. Maskin and Tirole focus on the steady state Markov equilibrium of an infinite-horizon game with discounting. They show that it is the limit of the finite-horizon case, with the dynamics again recursively generated from last-period Stackelberg reactions. (Both Cyert and de Groot and Maskin and Tirole suppose that firms set quantities, while we consider price as the decision variable in the models that will be presented in Sects. 3.1 and 4.)

In addition, Stackelberg reactions drive the steady state solution in Maskin and Tirole's model. Firm 1's reaction $p$ to 2 's price $q$ maximizes $\pi(p, q)+\delta U(p)$, where $\pi(p, q)$ is firm 1's within-period profit from setting price $p$ while its rival chooses price $q$, and $U(p)$ is the continuation value of the subgame with firm 1's price $p$ set for one period and its rival's turn to move. That continuation value is complex, but it does not depend on $q$-in that subgame, $q$ is already a bygone. Thus, firm 1's incentive for setting $p$ blends its incentives to respond to $q$ so as to maximize $\pi(p, q)$, which are exactly Stackelberg response incentives, with its incentives to maximize $U(p)$, a problem that is independent of $q$. By the implicit function theorem, the slope (or responsiveness) of the dynamic reaction of $p$ with respect to $q$ is given by $\frac{-\pi_{12}(p, q)}{\left[\pi_{11}(p, q)+U^{\prime \prime}(p)\right]}$, while that of the Stackelberg reaction is given by the same formula without the $U^{\prime \prime}(p)$. In each case the denominator is negative by the second-order condition. In particular the dynamic reaction has the same sign as the Stackelberg reaction. ${ }^{33}$

Thus, fully dynamic reaction functions can readily be driven by, and be related, to Stackelberg reactions. We do not claim that fully dynamic reactions are systematically close to Stackelberg. Indeed, Maskin and Tirole show in a limiting case that they may be substantially different. But we conjecture that in circumstances where Stackelberg reactions are relatively strong, actual non-purposive reactions will also tend to be strong, and conversely. ${ }^{34}$ We propose as a topic for future research identifying the circumstances under which Stackelberg reactions are reasonable proxies for firms' actual natural (non-purposive) reactions.

\footnotetext{
33 See Lemma 1 in Maskin and Tirole (1987). Moreover, the dynamic denominator is larger in absolute value than is the Stackelberg version- $\pi_{11}(p, q)$-if and only if $U(p)$ is (locally) concave in $p$, which is, therefore, the condition for the dynamic reaction to be weaker than the Stackelberg reaction; Maskin and Tirole show that this is the case in their example. While $U$ is complex and highly endogenous, it is the present-value payoff for a first mover, so an intuition that a first mover's present value payoff is concave in its choice of $p$ would imply that $U$ is concave for a later mover also. Maskin and Tirole also show that in their model as the discount factor converges toward 1 (coinciding with the limit of the Cyert-deGroot model as the number of periods grows) the tradeoff is not overwhelmed by the $U^{\prime \prime}$ term in the denominator (which would lead to near-zero dynamic responsiveness). In fact Maskin and Tirole calculate that the dynamic responsiveness is somewhat over half of the Stackelberg responsiveness.

${ }^{34}$ In somewhat the same spirit, Farrell and Shapiro (2010b) respond to the criticism that UPP is not a full-blown merger simulation by pointing out that "a ball that is kicked harder might not travel further... but as a general matter hard-kicked balls tend to [do so].".
} 
In Sect. 3.1 we use linear demand models to discuss the strength of the Stackelberg response and evaluate how it affects an initiator's pricing incentives. Subsequently in Sect. 3.1 and in Sect. 4 we modestly expand that framework to allow for a firm to offer more than one product or for there to be more than one follower firm. In those price-setting models, the reactions are "reinforcing" (Baker and Farrell 2020): The reaction to a change goes in the same direction as the motivating change. For example, rivals' reactions to a price cut generally involve price cuts. We do not analyze the case when rival reactions are "diluting" (going in opposite directions), as may arise in quantity-setting models (including Maskin and Tirole 1987).

These models raise the question of which firm is thought to move first. As we will see below, there is a sense in which a "small" firm will respond more strongly to, and intuitively therefore has more need to see, what its "big" rival is doing, than vice versa. That observation appears to resonate with the intuitive idea that bigger firms are apt to be leaders and small firms apt to be followers. But more work on that topic - and on timing with more than two players - would be valuable. Nor do these models (unlike Maskin and Tirole) study more than two periods.

\subsection{Stackelberg Responses and Diversion Ratios}

The incentive effects of Stackelberg reactions can be linked to the familiar antitrust concept of diversion ratios. Specifically, we show that with linear demand and constant marginal costs, the fraction by which own-elasticity for one good is reduced due to anticipation of a Stackelberg price response by the seller of a substitute, relative to own-elasticity under the Nash assumption of no response, is equal to half the product of the two diversion ratios between those goods. This technical point shows why diversion ratios may be relevant to understanding the consequences of mergers for non-purposive coordination-which will be the subject of Sect. 4.

We assume that each firm sells a single product, and assume linear demand for each product

$$
x_{i}=a_{i}-b_{i} p_{i}+c_{i} p_{j},
$$

and constant (normalized to 0 ) marginal costs, so $\pi_{i}=p_{i} x_{i}$. Firm 1 sets price $p_{1}$ and firm 2 responds with $p_{2}$.

How much does $p_{2}$ respond to $p_{1}$ ? Since the proximate cause of the response is the shift in firm 2's residual demand curve (making the response unambiguously non-purposive), we wouldn't expect much of a response if variation in $p_{1}$ doesn't do much to firm 2's residual demand-if there's not much substitution between the products. ${ }^{35}$ This of course doesn't prove that when there is a lot of substitution there

\footnotetext{
35 A caveat is that we might yet get a big response even if the shift in firm 2's residual demand is small, when firm 2's profit function (as a function of its price $p_{2}$ ) is very flat on top (i.e., if firm 2 is almost indifferent when setting its own price near the profit maximum). (This is the case where the denominator of (3.2) is small.) That in turn corresponds in this class of models to firm 2's having substantial market power: In simple parameterizations firm 2 's profit function is unlikely to be very flat on top if its maximizing price is close to its marginal cost.
} 
is a big response (and with iso-elastic demand there isn't), but the two commonly go together, and indeed they do so here. ${ }^{36}$

By the implicit function theorem we have generally:

$$
\frac{d p_{2}}{d p_{1}}=\frac{\frac{\partial^{2} \pi_{2}}{\partial p_{1} \partial p_{2}}}{-\frac{\partial^{2} \pi_{2}}{\partial p_{2}^{2}}} .
$$

When $x_{i}$ is linear in prices (so all its second derivatives are zero), both numerator and denominator of this fraction are proportional to first derivatives of demand:

$$
\frac{\partial^{2} \pi_{2}}{\partial p_{1} \partial p_{2}}=\frac{\partial x_{2}}{\partial p_{1}},
$$

and

$$
\frac{\partial^{2} \pi_{2}}{\partial p_{2}^{2}}=2 \frac{\partial x_{2}}{\partial p_{2}}
$$

(The right-hand side of (3.3) is positive when the products are substitutes. The right-hand side of (3.4) is negative for a normal good, and the left-hand side of (3.4) must be negative by the second order condition.)

Thus (3.2) is a half of the ratio of two first partial derivatives of demand for product 2:

$$
\frac{d p_{2}}{d p_{1}}=\frac{1}{2} \cdot \frac{\frac{\partial x_{2}}{\partial p_{1}}}{-\frac{\partial x_{2}}{\partial p_{2}}} .
$$

By (3.5), this response of $p_{2}$ to $p_{1}$ just halfway-undoes the impact of the change in $p_{1}$ on $x_{2}$.

If the marginal sales of both products 1 and 2 were all on the margin between those products, this would imply that the response halves the sensitivity of $x_{1}$ to $p_{1}$. But that would be a very special form of demand. A (small) response by firm 2 doesn't affect that part of the marginal sales of product 1 that is driven by nearindifference between product 1 and (say) product 3. Meanwhile, to the extent that the response by firm 2 affects marginal choices between product 2 and (say) product 4 , those need not affect the demand response for product 1 .

This discussion makes clear why diversion ratios enter into Stackelberg responses. Before continuing the calculation of the impact on firm 1's incentives, we note that Eq. (3.5) (and in particular, the $\frac{\partial x_{2}}{\delta p_{1}}$ term in the numerator) also indicates why one would typically expect $p_{2}$ to respond more strongly to a cut in $p_{1}$ when

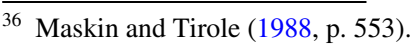


product 1 is a popular product: More of firm 2's customers are at risk than would be the case if product 1 is a less appealing or niche product.

With respect to the impact on firm 1's incentives, observe that an increase $d p_{1}$ in $p_{1}$ without a response by firm 2 would change product 1 's sales by $-\frac{\partial x_{1}}{\partial p_{1}}$. The response by firm 2 further changes product 1 's sales by $\frac{d p_{2}}{d p_{1}} \cdot \frac{\partial x_{1}}{\partial p_{2}}$. Using (3.5), that additional effect is equal to

$$
\frac{1}{2} \cdot \frac{\frac{\partial x_{2}}{\partial p_{1}}}{-\frac{\partial x_{2}}{\partial p_{2}}} \cdot \frac{\partial x_{1}}{\partial p_{2}}
$$

We calibrate the additional effect relative to the change in product 1's sales that would have ensued from the change in $p_{1}$ without firm 2's response: We divide expression (3.6) by $-\frac{\partial x_{1}}{\partial p_{1}}$, which yields:

$$
\frac{1}{2} \cdot \frac{\frac{\partial x_{2}}{\partial p_{1}}}{-\frac{\partial x_{2}}{\partial p_{2}}} \cdot \frac{\partial x_{1}}{\partial p_{2}} \cdot \frac{1}{-\frac{\partial x_{1}}{\partial p_{1}}}
$$

- which is half the product of the diversion ratios between products 1 and 2 .

This expression for the proportional reduction in the own-price derivative of demand also gives the proportional reduction in own-price elasticity of demand (at any given price and quantity, simply multiply both pre- and post-reduction derivatives by $\left[\frac{p}{x}\right]$ to obtain elasticities). Hence, with linear demand and constant marginal costs, the fraction by which the own-elasticity of demand for product 1 is reduced due to anticipation of a Stackelberg price response by product 2 (relative to ownelasticity under the usual Nash assumption of no response) is equal to half the product of the two diversion ratios (from product 1 to 2 and from 2 to 1 ) between those products.

For comparison, the "first round" unilateral-effect impact of a symmetric horizontal merger on pricing incentives for product 1 controlled by a merging firm can be represented (Shapiro 1996) as the loss of a fraction, equal to a diversion ratio between product 1 and the products of the other merging firm, of the own elasticity of demand for product 1. In our example the fractional discount to the Stackelberg response is not a diversion ratio but half of the product of two diversion ratios. The latter must be smaller (as diversion ratios between substitutes are between 0 and 1); how much smaller (and how small) of course varies with the diversion ratios.

We also discuss briefly how we would expect our analysis to change if firm 1 (the initiator) and/or firm 2 (the responder) has more than one relevant product. ${ }^{37}$

\footnotetext{
37 With merger analysis and the structural presumption in mind, it would be useful to study whether and how Stackelberg reactions are related to market concentration. We have not studied the relationship between Stackelberg reactions and diversion ratios with logit demand, where diversion ratios are related to market shares.
} 
First, if firm 2 controls multiple products, the responses by firm 2 will differ from the responses that would ensue if each of those products were separately controlled. One intuition on this is that to the extent firm 2's products are substitutes that would compete against each other if separately controlled, that would push prices close to cost and (thus) cause them not to be very sensitive to shifts in demand-which thereby reduces the extent to which product 1 's price could cause a Stackelberg response. Thus, when firm 2 controls multiple substitute products, that may tend to strengthen the price response of each of them, and thereby strengthen the elasticity-dampening effect of those responses on pricing incentives for product 1 .

Second, if firm 1 controls multiple products, each of which is a substitute for a product that is sold by firm 2 , then each pricing decision by firm 1 - say for product 1 -takes into account not only the impact on product 1 of firm 2 's response to a change in $p_{1}$, but also the impact on firm 1's product 2 . As our examples in Sect. 4 indicate, this internalization by firm 1 of indirect Stackelberg effects across its different products (substitutes for the same product that is sold by firm 2) creates an additional form of upward pricing pressure that is not included in the standard unilateral-effect calculation even for multiple products.

\section{Mergers in a Model of Three Symmetric Products}

To analyze mergers when firms have Stackelberg reactions, we work with the simple linear symmetric demand system in which demand for each product $i$ is

$$
x_{i}=2-p_{i}+d \sum_{j \neq i} p_{j},
$$

and we assume that marginal cost is independent of output and the same across firms; it is then harmless to normalize marginal cost to 0 . Here $d$ is the diversion ratio between any pair of products. From here on, we specialize to three products, as that is the smallest number of products for which a merger can exist that is not a merger to monopoly. We assume $d>0$, and assume $2 d<1$ to rule out the perverse possibility that an increase in all prices would increase demand.

If $p$ maximizes $p(A-B p)$, for any $\mathrm{A}$ and $\mathrm{B}$ that do not involve $p$, then the first-order condition is $2 p=A / B$. Thus for a single-product firm that sells product $i$ and observes (or correctly predicts) its rivals' prices, profit maximization implies:

$$
p_{i}=1+\frac{1}{2} d \sum_{j \neq i} p_{j}
$$


Hence when $p_{i}$ responds to $p_{j}$ the responsiveness (derivative) is $d / 2$, as already derived in Sect. 3 above. ${ }^{38}$

\subsection{Simultaneous-move Nash equilibrium (conventional unilateral effects)}

Consider a 3-to-2 merger, with the assumption of (Bertrand-)Nash price-setting conduct both pre- and post-merger. Below, we will compare this conventional unilateral-effect simulation versus simulations that involve Stackelberg reactions, which themselves endogenously generate non-zero conjectural variations.

\subsubsection{Pre-merger pricing}

From Eq. (4.2) plus symmetry, the symmetric simultaneous-move equilibrium price $p^{\text {Nash } 3}$ satisfies:

$$
2 p=2+2 d p
$$

Hence:

$$
p^{N a s h 3}=\frac{1}{(1-d)}
$$

\subsubsection{Post-merger pricing}

Suppose now that firms 1 and 2 merge, and play continues to be simultaneous-move Nash.

Because the merged firm's maximization problem is symmetric (as between products 1 and 2) and concave in each price, it will optimally choose to price those two products equally. So we look for $p_{1}=p_{2}=p_{12}$ (say) and $p_{3}$, such that (given $p_{3}$ ) $p_{12}$ maximizes the merged firm's profits, or equivalently maximizes its per-product profits:

$$
\max p\left(2-p+d p+d p_{3}\right)
$$

which yields

$$
2(1-d) p_{12}=2+d p_{3} .
$$

Simultaneously, given $p_{12}$, firm 3 chooses $p_{3}$ to maximize its profit. Since firm 3 is competing against two products that are both priced at $p_{12}$, that maximization implies:

\footnotetext{
38 Also observe that if all other firms set (or are expected to set) their prices at cost $(=0)$; or if $d=0$ (in which case other firms' prices are of no concern to firm $i$ ), firm $i$ 's profit-maximizing price is 1 . Accordingly we can think of $p=1$ as a kind of price benchmark or floor, and decompose prices into 1 plus an increment that is zero at $d=0$ (which here means that the increment is d times an expression).
} 


$$
p_{3}=1+d p_{12} \text {. }
$$

Solving those two equations yields

$$
p_{12}=\frac{2+d}{2-2 d-d^{2}}
$$

and

$$
p_{3}=\frac{2}{2-2 d-d^{2}} \text {. }
$$

\subsubsection{Comparing post-merger and pre-merger prices}

First consider the prices that are charged by the merging firms for products 1 and 2 . Comparing (4.8) versus (4.4), we have an absolute increase of

$$
\Delta p=\frac{d}{(1-d)\left(2-2 d-d^{2}\right)} .
$$

To a first-order approximation in $d$ (with the use of a Taylor approximation) the increase in price is $d p / 2$. This approximation is consistent with the upward pricing pressure index (UPP; see, e.g., Farrell and Shapiro 2010a, b) equal to $d p$ with $50 \%$ direct pass-through (linear demand). (The diversion ratio is $d$; and since we normalized costs to 0 , the merging partner's absolute gross margin is $p$.) The second-order effects that are ignored in that approximation are related to indirect pass-through and cross-pass-through, and to the merged firm's anticipation of the price change on the non-merging product, as is usual in such Nash-Bertrand merger calculations. ${ }^{39}$

As a proportion of the pre-merger price-from (4.4) - this merger-induced increase for products 1 and 2 is:

$$
\Delta \frac{p}{p^{\text {Nash } 3}}=\frac{d}{2-2 d-d^{2}} .
$$

The price increase for the non-merging product 3-when we compare (4.9) with (4.4) — is in absolute terms:

$$
\Delta p=d^{2} \frac{1}{(1-d)\left(2-2 d-d^{2}\right)} .
$$

\footnotetext{
39 The Nash assumption that each firm optimizes while taking others' actions as given (when contemplating varying its own action) does not mean that any of the players' actions is unaffected by changes in the game, including merger. The actions of a non-merging firm-whose payoffs are not directly affected by the merger-are typically affected by its expectations of how other firms (in particular the merging firms) will change their actions. Also potentially confusing is the technical use of "best response" or "reaction" functions to calculate Nash equilibria despite the fundamental Nash principle that each player takes others' actions as given and there are no "responses" or "reactions".
} 
Here firm 3 responds according to (4.2) to its anticipation of the price increases given by (4.10) for products 1 and 2 (because it is responding to the prices of two other products, the factor of [1/2] in Eq. (4.2) vanishes). This is second-order in $d$, because it is a response to anticipation of the shift in demand for product 3 caused by the first-order (in $d$ ) anticipated competitive effect on the prices of goods 1 and 2 . The shift in demand is related to the change in prices via a second factor $d$, as was described in Sect. 3 above.

As a proportion of the pre-merger price, this price increase on the non-merging product (product 3 ) is

$$
\Delta \frac{p}{p^{\text {Nash } 3}}=\frac{d^{2}}{2-2 d-d^{2}}
$$

\subsection{Merger between Firms 1 and 2 that Creates a Stackelberg Leader}

Suppose next that pre-merger the three firms play Nash in prices, as above, but that after a merger between Firms 1 and 2, the merged (and big) firm acts as Stackelberg leader in price, with Firm 3 following or responding.

We have already calculated pre-merger Bertrand-Nash prices in Eq. (4.4).

Post-merger, recall from (4.2) how firm 3 will respond to observing $\left(p_{1}, p_{2}\right)$ :

$$
p_{3}=1+\frac{d\left(p_{1}+p_{2}\right)}{2} .
$$

Because this is a response to observing the merged firm's prices $\left(p_{1}, p_{2}\right)$ (not a response to anticipating their Nash equilibrium values), the merged firm can affect $p_{3}$ through its choice of $\left(p_{1}, p_{2}\right)$.

By symmetry and concavity, we can assume that the merged firm sets symmetric prices $p_{1}=p_{2}=p_{12}$, and that the uniform price is set to maximize the sum of product 1 's and product 2 's profits:

$$
2 p(2-p+d p+d[1+d p]) .
$$

Maximizing (4.13) yields

$$
p_{1}=p_{2}=p_{12}=\frac{1}{2} \frac{2+d}{1-d-d^{2}}=1+d \frac{3+2 d}{2\left(1-d-d^{2}\right)} .
$$

From (4.12) and (4.14), we can write 3's post-merger price:

$$
p_{3}=\frac{1}{2} \frac{2-d^{2}}{1-d-d^{2}} .
$$

These post-merger prices are higher than those in the case that we first considered where Bertrand-Nash conduct continued after the merger. Since the pre-merger industry was assumed to be the same (i.e., 3-way symmetric Bertrand-Nash), that 
implies that the merger has stronger anticompetitive effects when it makes the merged firm a leader.

To evaluate the change in the prices for the merging firm's products (1 and 2), we compare Eq. (4.14) with Eq. (4.8). The expressions are the same except that in Eq. (4.8) the denominator is $2-2 d-d^{2}$ and in Eq. (4.14) it is $2-2 d-2 d^{2}$. Thus, the merged firm's post-merger prices are higher in the case where it has become a leader, to a degree that is increasing in $d$ : both because higher $d$ makes $d^{2}$ larger and because the difference between the denominators matters more the smaller they are.

The price that is charged by the non-merging firm-firm 3-responds to the prices that are charged in equilibrium by the merged firm, so that price too is higher after the merger that creates a leader than after the merger that left Bertrand-Nash conduct in place.

To understand why the merged firm's prices are higher, it is helpful to decompose the price effects of merger into two parts: one that arises from assuming zero conjectural variations (as in the usual model of unilateral effects); and an additional effect that reflects its anticipation of the non-merging firm's response. The first effect is the way that the merger between 1 and 2 internalizes the direct diversion effect on 2 of changes in $p_{1}$, which we can write essentially as standard UPP (though here as a shadow gain from price increase, rather than as a shadow cost of an incremental unit of output). A unit increase in $p_{1}$ raises the demand curve for product 2 by $d$, and by the envelope theorem the impact on the profits of product 2 can be calculated as the incremental profit (at a constant price) from that demand boost:

$$
\frac{\partial \pi_{2}}{\partial p_{1}}=p_{2} d
$$

Added here is that when the merger also makes the merged firm a leader, it also internalizes a second effect of changes in $p_{1}$ on the profits of product 2: the effect via induced changes in $p_{3}$ :

$$
\frac{d p_{3}}{d p_{1}} \frac{\partial \pi_{2}}{\partial p_{3}}=\frac{d}{2} d p_{2}
$$

With Bertrand-Nash conduct, by contrast, the price of product 3 responds to the expected price changes resulting from the merger but post-merger the leader cannot induce a different response by varying the actual prices of products 1 and 2 , so there is no such effect to internalize.

\subsection{Merger that Expands a Pre-existing Leader}

We can also analyze a merger between Firms 1 and 2 when Firm 1 was already a Stackelberg price leader, and acquires one of its two followers. This yields the same post-merger outcome, including prices, as the merger that we just considered; but it starts from a different pre-merger form of conduct (with firm 1 a leader while firms 2 and 3 simultaneously follow), which generates different pre-merger equilibrium pricing. 
Pre-merger, firm 1 sets $p_{1}$ anticipating the simultaneous response that constitutes an equilibrium in a subgame between 2 and 3. Given (say) firm 2's observation of $p_{1}$ and its anticipation of $p_{3}$, firm 2 sets $p_{2}$ so that:

$$
2 p_{2}=2+d p_{1}+d p_{3} .
$$

Similarly for firm 3:

$$
2 p_{3}=2+d p_{1}+d p_{2} \text {. }
$$

Hence $p_{2}$ and $p_{3}$ simultaneously respond to $p_{1}$ according to:

$$
p_{2}=p_{3}=\frac{2+d p_{1}}{2-d}=1+d \frac{1+p_{1}}{2-d} .
$$

Taking this response into account, $p_{1}$ is chosen to maximize:

$$
p\left(2-p+2 d \frac{2+d p}{2-d}\right)=\frac{p}{2-d}\left(2(2-d)+4 d-\left((2-d)-2 d^{2}\right) p\right)
$$

which gives

$$
p_{1}=\frac{2+d}{2-d-2 d^{2}}=1+d \frac{2+2 d}{2-d-2 d^{2}}
$$

And $p_{2}$ and $p_{3}$ can be calculated from (4.20) and (4.22):

$$
\begin{gathered}
p_{2}=p_{3}=\frac{2+d \cdot \frac{2+d}{2-d-2 d^{2}}}{2-d}=\frac{2\left[2-d-2 d^{2}\right]+d(2+d)}{(2-d)\left[2-d-2 d^{2}\right]} \\
=\frac{4-3 d^{2}}{(2-d)\left(2-d-2 d^{2}\right)} .
\end{gathered}
$$

Again this exceeds the Nash price for $d>0$. It is intuitive that in such price-setting markets, Stackelberg prices will exceed Bertrand-Nash prices. Giving the leader the ability to cause a response in the direction of matching a change encourages a price increase; then the ordinary Bertrand-Nash indirect effects reinforce that increase.

\subsection{Discussion}

In the examples of three-product conduct and mergers modeled above, both the premerger prices and the proportional merger effect on prices are higher in the Stackelberg models than in the conventional unilateral effect analysis- the Nash-Bertrand model — and the difference tends to grow as diversion ratios increase. ${ }^{40}$ We do not

${ }^{40}$ Given the demand system (4.1), the change in consumer surplus from any change in the price vector $p$ $=\left(p_{1}, p_{2}, p_{3}\right)$ is equal to the change in a quadratic function $s\left(p_{1}, p_{2}, p_{3}\right)$ of the three prices:

$$
s\left(p_{1}, p_{2}, p_{3}\right) \equiv \iiint_{0}^{p} \sum_{i=1,2,3}-\left[x_{i} d p_{i}\right]=\frac{1+d}{2} \sum_{i} p_{i}^{2}-2 \sum_{i} p_{i}-\frac{d}{2}\left[\sum_{i} p_{i}\right]^{2} .
$$


know to what extent this result (or the others above) generalizes beyond the conditions in our model. It cannot hold universally, since the outcome of monopoly is a symmetric ceiling.

Nevertheless, we think that the modeling above suggests an additional degree of concern about highly concentrating mergers that are short of monopoly relative to the Nash-Bertrand analysis (whether predicting post-merger prices based entirely on fundamentals or predicting proportional price increases off observed pre-merger prices). At a minimum, the modeling points to the potential for significant errors if the Nash-Bertrand model is used to estimate merger price effects (with, let's say, a reliable estimate of the demand system including diversion ratios) when Stackelberg conduct (or non-purposive responses that are related to Stackelberg conduct) is present both pre- and post-merger. Our model suggests a way of addressing effects of a merger that would cause a regime shift from approximately Nash conduct to substantial conjectural variations (e.g., Ordover et al. 1982), as for instance in Stackelberg conduct.

It would be particularly useful for policy-making purposes to understand: how the divergence between post-merger prices with Stackelberg and Nash reactions varies with diversion ratios between products/firms; how the models diverge under different ways of modeling demand (such as a logit demand system, in which diversion ratios are related to market shares); and whether the results change if the firms set quantities rather than prices. For example, in our price-setting model reactions are reinforcing, and the merger harms competition by strengthening them. It would be useful to know whether similar conclusions arise when reactions are diluting (as in quantity-setting models) and the merger harms competition by weakening those responses.

Understanding the difference between Stackelberg and Nash outcomes is important for understanding when and to what extent Nash equilibrium models understate the competitive threat from mergers in settings where non-purposive coordination is likely.

\section{Conclusion}

Our paper identifies a number of important research topics that are raised by the way that the Merger Guidelines treat coordinated competitive effects. With respect to purposive coordination, we suggest some ways that the economics literature could move toward greater realism and toward quantification of competitive effects.

\footnotetext{
Footnote 40 (continued)

We call $s\left(p_{1}, p_{2}, p_{3}\right)$ the consumer surplus function. (There is nothing canonical about starting the integration at zero prices rather than some other fixed benchmark-only differences in the consumer surplus function, $\Delta s\left(p_{1}, p_{2}, p_{3}\right)$, not levels, count for our purposes-but it makes the notation a little easier. It does, however, imply that when all prices are positive, measured consumer surplus is negative.) In principle, we could calculate the change in $s\left(p_{1}, p_{2}, p_{3}\right)$ that is due to each merger that is modeled. That would be an appropriate summary statistic for the consumer impact of a merger that affects different prices differently. We leave this topic for future research.
} 
Table 1 Pricing dynamics

\begin{tabular}{llll}
\hline Day & Firm 1 & Firm 2 & Firm 3 \\
\hline 1 & 1 & 0 & 0 \\
2 & 1 & .5 & 0 \\
3 & 1 & .5 & .75 \\
4 & .625 & .5 & .75 \\
5 & .625 & .6875 & .75 \\
\hline
\end{tabular}

We also point out that the 2010 Guidelines sensibly endorsed the possibility that a horizontal merger could harm competition through its effects on non-purposive coordination: by increasing the strength of natural and predictable rival responses when those reactions are reinforcing, or by reducing the strength of such responses when they are diluting. Industrial organization economics does not yet proffer a robust and tractable workhorse model for gauging the strength of oligopoly responses, purposive or non-purposive. But it is certainly unsatisfactory either to assume that responses do not occur (as with standard unilateral-effects models) or to raise in principle, but then heavily discount in practice, the possibility that responses are startlingly strong (as with folk-theorem models). Merger economics needs better workhorse models than those.

We have suggested a possible direction for making more realistic the workhorse model of oligopoly supergames, and note that the 2010 Guidelines provide a verbal description of non-purposive coordination. As an exploratory step toward more specifics on the latter, we observe that such reactions could themselves be Stackelberg reactions, and suggest more broadly that they have much in common with, and could plausibly thus be proxied for with, Stackelberg reactions. This suggestion motivated our explorations of the extent to which Stackelberg reactions affect price-setting incentives, and of differences between the outcomes of mergers in Stackelberg models and in Nash models. The "Appendix" presents a different, more behavioral picture of parallel accommodating conduct. Our models are initial explorations, and suggest an agenda for economic research.

Table 1 illustrates price dynamics for $n=3$ for days 1 through 5 , with those normalizations:

\section{Appendix: Mean-Matching Model}

Here we describe a simple behavioral model of price dynamics in an oligopoly in which (exogenously) firms take turns having opportunities to adjust price, and at each such opportunity the firm whose turn it is sets its price to the mean of others' prices. We first analyze the equilibrium of the model, then turn to the effects of mergers.

We do not claim that the behavioral rule that we study is optimal behavior; but it seems loosely and qualitatively to capture a part of how oligopolists may 
behaviorally respond to price changes by rivals (consistent with some reported evidence on available pricing algorithms—-see Brown and MacKay 2020). ${ }^{41}$

Given that behavioral dynamic, it is a steady state (or "equilibrium," in a dynamic but not incentive-based sense) if all firms charge the same price: $p_{0}$. We consider moves away from such a steady state.

We first study the dynamics of convergence to a (new) steady state when an initiating firm moves its price away from an initial steady state, and reactions thereafter consist of each firm (including the initiator) in turn matching the mean price of all others.

While this is a non-optimizing "behavioral" model of dynamics, we are interested in the tradeoff that faces the initiating firm when it can lead the industry to a new and higher uniform steady-state price but during the readjustment or re-equilibration process is generally higher-priced than are its competitors. Equivalently (changing sign), we are concerned with the tradeoff when an initiating firm cuts its price and consequently is temporarily lower-priced than are its competitors during re-equilibration, but in the end the uniform market-wide price is lower than it had been. (Implicitly, therefore, we are considering prices below the monopoly price, so that it is more profitable for all to all have higher prices within this range.) We do not explicitly model the initiator's preferences over that tradeoff, but instead consider how structure affects the available "terms of trade" that it faces.

Thus, consider an initial steady state in which all firms, $1, \ldots, n$ price at $p_{0}$. Now on "day 1 " firm 1 disrupts that initial steady state by changing its price to $p_{0}+\Delta$. On day 2, firm 2 gets the opportunity to re-set its price, and re-sets to the mean of its rivals' prices (including firm 1 's): to the mean of $\left(p_{0}+\Delta, p_{0}, p_{0}, \ldots, p_{0}\right)$. Thus firm 2 's new price is $p_{0}+\frac{1}{n-1} \Delta$. On day 3 , firm 3 adjusts its price to the mean of its rivals' prices, which is $p_{0}+\left[\frac{1}{n-1}\left[1+\frac{1}{n-1}\right]\right] \Delta$. And so on.

Observing that everything takes the form $p_{0}+k \Delta$, we can simplify by taking $p_{0}=0$ and $\Delta=1$, or to put it another way, by recording price departures from $p_{0}$ as fractions of the initiator's initial departure from $p_{0}$. Then we can use numerical calculations to explore the price dynamics (Table 1).

Following the one-time departure from price-matching, the maximum of the prices can only decrease, and the minimum can only increase. After 20 days (not shown here) the three prices are, to six decimal places, 0.666664, 0.666666, and 0.666668 . We think it is reasonable to conclude that the prices are converging to $2 / 3$.

We did corresponding numerical calculations for $2 \leq n \leq 10$ (and with more days for the larger values, so as to get credible near-convergence). ${ }^{42}$ While we do not have algebraic results, the numerical results track closely the description that with $n$ firms, prices numerically converge to a new steady state at price $2 / n$. Recalling our normalizations, we restate this as:

\footnotetext{
41 The simple linear-demand model with Stackelberg reactions in the text turns out (Eq. 4.2) to have partial matching.

42 We thank Berkeley undergraduate Angela Jing for running the calculations. After we developed and presented this model at the 2020 Berkeley-Stanford IOFest, a Stanford graduate student, Lulu Wang, calculated a continuous-time formulation.
} 
With $n$ firms, if we start at a uniform steady-state price $p_{0}$ and one firm initiates a disequilibrium by increasing its price by $\Delta$, prices re-converge to a new steady state at price $p_{0}+(2 / n) \Delta$.

If $\Delta>0$, the higher uniform (steady state) price will normally be more profitable for each firm than the lower initial price if the higher price is not above the joint monopoly price. But what did the initiating firm 1 have to suffer in order to improve its own - and its rivals' - steady-state profits? It had to "lead" the price increase; and (while we do not model this explicitly) one might expect that it would lose customers to its rivals during that "leadership," and wouldn't necessarily get them back after prices converge. We consider this tradeoff here.

Assume that it is costly in terms of market share for a firm to have a higher price than the mean of its rivals' prices, and that this cost aggregates linearly across days. Then a measure of that cost for the initiating firm 1 is the undiscounted sum of its "pricing disadvantage" relative to its rivals, day by day, until the sum converges. (We do not discount, for simplicity and also because one might expect these "days" to be short and, in the range we consider, not very many days are needed for effective convergence.) It is not immediate (even given that prices converge to each other and to a new steady state) that this open-ended sum also converges; but, again, our numerical calculations indicate that it does. Those calculations are (again, numerically rather precisely with a couple of dozen days when $n$ is fairly small) consistent with the summary that with $n$ firms, the initiator's cumulative pricing disadvantage numerically converges to $[n-1]$. Recalling our normalizations, we restate this as:

With $n$ firms, the initiator's cumulative pricing disadvantage numerically converges to $(n-1) \Delta$.

Since this cumulative pricing disadvantage is the sum over days of the intra-day pricing disadvantage, it is thus measured in [\{dollars-per-widget $\}$ times days]. If we are comparing across different values of $n$, we are implicitly holding fixed the length (in terms of the hemorrhage of a higher-priced firm's market share) of a "day" across that comparison. That might be appropriate; or, alternatively, it might make more sense to hold fixed the length of what we might call informally a "week"- the $n$ - "day" period between any one firm's (e.g., firm 1's) successive opportunities to adjust its price. In that case, the cumulative pricing disadvantage would converge to $(n-1) \Delta / n$ dollars-per-widget-weeks.

Because $\Delta$ is a free choice variable, the absolute magnitude of the pricing disadvantage or of the change in steady-state price that is due to the initial departure of one firm's price by $\Delta$ is not meaningful in itself. What is economically meaningful is their ratio for a given $\Delta$, which measures the "terms of trade" that face a firm that contemplates initiating a change. Given the results above, it follows that:

With $n$ firms, the initiator of a price increase incurs a cumulative pricing disadvantage (using the measure with days) equal to $n(n-1) / 2$ times the steady-state price increase achieved.

Or, if we focus instead on price cuts (negative $\Delta$ ):

The initiator of a price cut reduces the steady-state price by $2 /[\boldsymbol{n}(\boldsymbol{n}-1)]$ times the cumulative pricing advantage (in days) that it captures. 
Table 2 Pricing dynamics following merger

\begin{tabular}{llll}
\hline Day & Firm 1-and-2 & Firm 3 & Firm 4 \\
\hline 1 & 1 & 0 & 0 \\
2 & 1 & .6667 & 0 \\
3 & 1 & .6667 & .88889 \\
4 & .77778 & .66667 & .88889 \\
5 & .77778 & .814815 & .88889 \\
6 & .77778 & .814815 & .79012 \\
\hline
\end{tabular}

These ratios quantify how the terms of trade favor a price cut more (starting from any given uniform steady-state price) and favor a price increase less, the larger is $n$. If we measure the cumulative pricing disadvantage using weeks rather than days, the ratios tell the same qualitative story but less strongly: instead of $n(n-1) / 2$, we have $(n-1) / 2$, etc.

This suggests more competitive pricing in markets with a larger $n$, without having explicitly to model the specific impacts on profits. Because the tradeoff shifts uniformly with an increase in $n$, fewer potential initiators of price increases will find the tradeoff appealing, and more potential initiators of price cuts will do so. As the 2010 HMG put it:

[Reactions by rivals] “can blunt a firm's incentive to offer customers better deals by undercutting the extent to which such a move would win business away from rivals. They can also enhance a firm's incentive to raise prices, by assuaging the fear that such a move would lose customers to rivals."

Next we consider the effect of a merger in this model. Suppose we begin with $n$ symmetric single-product firms, and two of them (firms 1 and 2) merge, without changing the set of products offered. (This corresponds to the standard idea in merger analysis of considering a change in control of a given set of products.) We consider the merged firm as an initiator of a price increase. (We have not studied the consequences of merger when a non-merging firm is the potential initiator.)

We continue to assume that each non-merging firm in turn matches the average of others' products, which is to say it matches a weighted average of rivals' prices, so that the merged firm's price (as it applies to two products) gets double weighting. We also assume that, in its turn, the merged firm adjusts both of its prices simultaneously to match the average price of the non-merging firms' products (this is different from continuing the pre-merger product-by-product conduct of the merged products).

Then, illustrating with $n=4$, we get (Table 2):

Again, based on carrying these numerical calculations to the point where convergence appears to have occurred, for $n$ ranging up to 10, we find:

With $n$ products, sold by $(n-1)$ firms, one of which is twice the size of each of the remaining firms, following a price increase of 1 that is initiated by the large firm, the steady-state price increases by $4 /(n+1)$ and the initiator's cumulative pricing disadvantage is $(n-1)^{2} /(n+1)$ (measured using days). Thus, the ratio-the pricing disadvantage that is incurred per unit of steady-state price increase-is $(n-1)^{2} / 4$. 
Compare this ratio with the previously derived corresponding "pre-merger" ratio of pricing disadvantage to steady-state price increase with $n$ independently controlled products, which was $n(n-1) / 2$. The pre-merger ratio is $2 n /(n-1)$ times the post-merger ratio. ${ }^{43}$ Thus, the merger has created a firm that will be more tempted to increase price (from any particular level) and less tempted to cut price than were any of the pre-merger firms, especially for relatively concentrated industries ( $\operatorname{small} n$ ).

Acknowledgements The authors are indebted to Joe Harrington, Louis Kaplow, Al Klevorick, Alex MacKay, Adrian Majumdar, Leslie Marx, Nate Miller, Robert Porter, Michael Salinger, Steve Salop, Richard Schmalensee, Carl Shapiro and Bobby Willig, and to participants in Berkeley-Stanford IOFest and the University of Cambridge-University of Florida Antitrust Virtual Workshop Series.

\section{References}

Abreu, D. (1986). Extremal equilibria of oligopolistic supergames. Journal of Economic Theory, 39, 191-225.

Abreu, D., Milgrom, P., \& Pearce, D. (1991). Information and timing in repeated partnerships. Econometrica, 59(6), 1713-1733.

Bain, J. S. (1968). Industrial organization (2nd ed.). New York: Wiley.

Baker, J. B. (1996). Identifying horizontal price fixing in the electronic marketplace. Antitrust Law Journal, 67, 41-55.

Baker, J. B. (2002). Mavericks, mergers, and exclusion: Proving coordinated competitive effects under the antitrust laws. New York University Law Review, 77, 135-203.

Baker, J. B. (2003). Why did the antitrust agencies embrace unilateral effects? George Mason University Law Review, 12, 31-38.

Baker, J.B. (2010). Market concentration in the antitrust analysis of horizontal mergers. In Keith Hylton (Ed.), Antitrust Law \& Economics (pp. 234-60), corrected working paper available at http://ssrn. com/abstract $=1092248$.

Baker, J. B. and Farrell, J. (2020). Oligopoly coordination, economic analysis, and the prophylactic role of horizontal merger enforcement. University of Pennsylvania Law Review (forthcoming)

Baxter, W. F. (1983). Responding to the reaction: The draftsman's view. California Law Review, 71, 618-631.

Bernheim, B. D., \& Ray, D. (1989). Collective dynamic consistency in repeated games. Games and Economic Behavior, 1, 295-326.

Bresnahan, T. F. (1981). Duopoly models with consistent conjectures. American Economic Review, 71, 934-945.

Brown, Z., and MacKay, A. (2020), Competition in Pricing Algorithms, working paper, Harvard Business School.

Calvano, E., Calzolari, G., Denicolò, V., \& Pastorello, S. (2020). Artificial intelligence, algorithmic pricing, and collusion. American Economic Review, 110, 3267-3297.

Chamberlin, E. H. (1962). The theory of monopolistic competition (8th ed.). Cambridge, Mass.: Harvard University Press.

Corts, K. S. (1999). Conduct parameters and the measurement of market power. Journal of Econometrics, $88,227-250$.

Cyert, R., \& DeGroot, M. (1970). Multiperiod decision models with alternating choice as a solution to the duopoly problem. Quarterly Journal of Economics, 84(3), 410-429.

Dixon, H. D., \& Somma, E. (2002). The evolution of consistent conjectures. Journal of Economic Behavior and Organization, 51, 523-536.

\footnotetext{
${ }^{43}$ We do not understand the factor 2 here, and it suggests a substantial effect even for large $n$. It might be tempting to attribute its presence to the fact that the merged firm captures the price increase on both of its products; but it also suffers the cumulative interim pricing disadvantage on both of its products.
} 
Daughety, A. F. (1985). Reconsidering cournot: The cournot equilibrium is consistent. RAND Journal of Economics, 16, 368-379.

Dockner, E. J. (1992). A dynamic theory of conjectural variations. Journal of Industrial Economics, 40, 377-395.

Farrell, J. and Maskin, E. (1989). Renegotiation in Repeated Games. Games and Economic Behavior 1

Farrell, J. and Shapiro, C. (2010a). Antitrust evaluation of horizontal mergers: an economic alternative to market definition. Berkeley Electronic Press.

Farrell, J. and Shapiro, C. (2010b). Upward pricing pressure and critical loss analysis: response. Competition Policy International Antitrust Journal.

Friedman, J. W., \& Mazzetti, C. (2002). Bounded rationality, dynamic oligopoly, and conjectural variations. Journal of Economic Behavior \& Organization, 49, 287-306.

Fudenberg, D., \& Tirole, J. (1991). Game theory. London: MIT Press.

Genesove, D., \& Mullin, W. P. (2001). Rules, communication, and collusion: Narrative evidence from the sugar institute case. American Economic Review, 91, 379-398.

Green, E. J., \& Porter, R. H. (1984). Noncooperative Collusion Under Imperfect Price Competition. Econometrica, 52, 87-100.

Harrington, J. (2014). Evaluating mergers for coordinated effects and the role of "parallel accommodating conduct." Antitrust Law Journal, 78, 651-668.

Kaplow, L. (2013). Competition policy and price fixing. Princeton: Princeton University Press.

Kühn, K. (2004). The coordinated effects of mergers in differentiated products markets. Law \& Economics Working Papers Archive: 2003-2009, 34. Retrieved from http://repository.law.umich.edu/ law_econ_archive/art34.

Levenstein, M. C., \& Suslow, V. Y. (2006). What determines cartel success? Journal of Economic Literature, 44, 43-95.

Lindh, T. (1992). The inconsistency of consistent conjectures. Journal of Economic Behavior and Organization, 18, 69-80.

Liu, Y., Ni, Y. X., Wu, F. F., \& Cai, B. (2007). Existence and uniqueness of consistent conjectural variation equilibrium in electricity markets. Electrical Power and Energy Systems, 29, 455-461.

Martin, S. (1993). Advanced industrial economics. Cambridge, MA: Blackwell Publishers.

Maskin, E., \& Tirole, J. (1987). A theory of dynamic oligopoly III: Cournot competition. European Economic Review, 31, 947-968.

Maskin, E., \& Tirole, J. (1988). A theory of dynamic oligopoly, I: Overview and quantity competition with large fixed costs. Econometrica, 56, 549-569.

Maskin, E., \& Tirole, J. (2001). Markov Perfect Equilibrium. Journal of Economic Theory, 100, 191-219.

Moresi, S., Reitman, D., Salop, S. C., and Sarafidis, Y. (2015). cGUPPI: Scoring incentives to engage in parallel accommodating conduct. Georgetown Law Faculty Publications and Other Works No. 1501. Retrieved from https://scholarship.law.georgetown.edu/facpub/1501.

Office of Fair Trading (UK) (2011). Conjectural variations and competition policy: Theory and empirical techniques. Retrieved Dec 31, 2020 from https://web.archive.org/web/20120511101929/; http://oft. gov.uk/shared_oft/research/CV_Competition_Policy.pdf.

Ordover, J. A., \& Willig, R. D. (1983). The 1982 Department of Justice merger guidelines: An economic assessment. California Law Review, 71(2), 535-574.

Ordover, J. A., Sykes, A. O., \& Willig, R. D. (1982). Herfindahl concentration, rivalry, and mergers. Harvard Law Review, 95, 1857-1874.

Perry, M. K. (1982). Oligopoly and consistent conjectural variations. Bell Journal of Economics, 13, 197-205.

Porter, R. H. (1985). On the incidence and duration of price wars. Journal of Industrial Economics, 33, $415-426$.

Porter, R. (2020) Mergers and coordinated effects. International Journal of Industrial Organization, forthcoming.

Possajennikov, A. (2015). Conjectural variations in aggregative games: An evolutionary perspective. Mathematical Social Sciences, 77, 55-61.

Schelling, T. (1960). The strategy of conflict. Cambridge, MA: Harvard University Press.

Schmalensee, R. (2012). "On a level with dentists?" Reflections on the evolution of industrial organization. Review of Industrial Organization, 41, 157-179.

Shapiro, C. (1989). Theories of oligopoly behavior. In R. Schmalensee \& R. Willig (Eds.), Handbook of industrial organization (Vol. 1, pp. 329-414). Amsterdam: North-Holland.

Shapiro, Carl (1996). Mergers with differentiated products. Antitrust, Spring, 23-30. 
Stigler, G. J. (1964). A theory of oligopoly. Journal of Political Economy, 72, 44-61.

Turner, D. F. (1962). The definition of agreement under the Sherman act: Conscious parallelism and refusals to deal. Harvard Law Review, 75, 655-706.

Willig, R. D. (1991). Merger analysis, industrial organization theory, and merger guidelines. Brookings Papers: Microeconomics, 1991, 281-332.

Publisher's Note Springer Nature remains neutral with regard to jurisdictional claims in published maps and institutional affiliations. 